\title{
The impact of monitoring techniques on progression to chronic breast cancer-related lymphedema: a meta-analysis comparing bioimpedance spectroscopy versus circumferential measurements
}

\author{
Chirag Shah ${ }^{1}$ (1) $\cdot$ April Zambelli-Weiner ${ }^{2} \cdot$ Nicole Delgado $^{2} \cdot$ Ashley Sier $^{2} \cdot$ Robert Bauserman $^{2} \cdot$ Jerrod Nelms $^{2}$
}

Received: 7 September 2020 / Accepted: 20 October 2020 / Published online: 27 November 2020

(c) The Author(s) 2020

\begin{abstract}
Background Chronic breast cancer-related lymphedema (BCRL) is a potentially serious complication following treatment. Monitoring for progression to BCRL may allow for earlier detection and intervention, reducing the rate of progression to chronic BCRL. Therefore, the purpose of this meta-analysis is to evaluate the impact of monitoring techniques on the incidence of chronic BCRL among patients monitored by bioimpedance spectroscopy (BIS) and circumference as compared to background rates.

Methods Eligible peer-reviewed studies from PubMed, CINHAL, or Google Scholar that were published in English from 2013 onward and conducted in North America, Europe, or Oceania. Incidence rates abstracted from studies were classified by BCRL monitoring method: background (no standardized BIS or circumference assessments), BIS or circumference. A random-effects model was used to calculate a pooled annualized estimate of BCRL incidence while accounting for clinical and methodological heterogeneity. Subgroup analyses examined differences in duration of follow-up as well as breast and axillary surgery.

Results 50 studies were included, representing over 67,000 women. The annualized incidence of BCRL was $4.9 \%$ (95\% CI: 4.3-5.5) for background studies ( $n=35), 1.5 \%$ (95\% CI: 0.6-2.4) for BIS-monitored studies $(n=7)$, and 7.7\% (95\% CI: 5.6-9.8) for circumference-monitored studies $(n=11)$. The cumulative BCRL incidence rate in BIS-monitored patients was $3.1 \%$ as compared to $12.9 \%$ with background monitoring (69\% reduction) and $17.0 \%$ with circumference-monitored patients ( $81 \%$ reduction).

Conclusions Evidence suggests that monitoring with BIS allowing for early intervention significantly reduces the relative risk of chronic BCRL with a $69 \%$ and $81 \%$ reduction compared to background and circumference, respectively. Circumference monitoring did not appear to provide a benefit with respect to chronic BCRL incidence. Based on these results, BIS should be considered for BCRL screening in order to detect subclinical BCRL and reduce rates of chronic BCRL, particularly in high-risk patients.
\end{abstract}

Keywords Breast cancer $\cdot$ Lymphedema $\cdot$ Axillary dissection $\cdot$ Bioimpedance

\section{Introduction}

Electronic supplementary material The online version of this article (https://doi.org/10.1007/s10549-020-05988-6) contains supplementary material, which is available to authorized users.

Chirag Shah

shahc4@ccf.org

1 Department of Radiation Oncology, Taussig Cancer Institute, Cleveland Clinic, Cleveland, OH, USA

2 TTi Health Research and Economics, Westminster, MD, USA
Lymphedema is a common and potentially serious complication of breast cancer (BC) treatment and has been associated with the extent of breast and axillary surgery, regional nodal irradiation (RNI), and taxane-based chemotherapy. [1-3] A recent meta-analysis reported that breast cancerrelated lymphedema (BCRL) affects approximately $19 \%$ of breast cancer patients with follow-up $\geq 12$ and $<24$ months after treatment. Significant heterogeneity in BCRL incidence rates exists due to different monitoring methods, follow-up periods, patient BCRL risk profiles, and study designs. [1, 
4] Patients with chronic BCRL have reduced quality of life which can be attributed to functional impairment or disability, discomfort, and infection, as well as higher medical costs. [1, 2, 5-7] Psychologically, chronic BCRL may also cause anxiety, depression, and social difficulty. $[1,2,4]$ It is therefore important to identify BCRL early, in the subclinical phase of the process, allowing for earlier intervention, thereby reducing the development of the severe and irreversible symptoms of chronic BCRL. [5] In particular, patients who undergo mastectomy, axillary lymph node dissection (ALND), RNI, or taxane-based chemotherapy have an increased risk of developing BCRL and with being highrisk would benefit from prospective BCRL assessment. [8]

There are several different methods commonly used to detect for and monitor BCRL including tape measurement and water displacement $[5-7,9]$. Both of these methods are considered standard for lymphedema monitoring. [7] However, these methods can be highly variable and prone to bias from human measurement, resulting in inter- and intraobserver variability, while being less able to detect subclinical BCRL. [7, 10] Bioelectrical impedance (bioimpedance) or bioimpedance spectroscopy (BIS) has emerged as a promising diagnostic tool, able to objectively quantify BCRL by measuring resistance to electrical current flow through a patient's body, giving a more accurate and consistent representation of body composition, and aiding in the assessment of subclinical BCRL earlier than standard methods. [5, 6, 8, 9] Due to the capability of BIS to aid in the assessment of subclinical lymphedema and trigger early intervention, it can potentially reduce the rate of progression to chronic BCRL (clinically assessed BCRL occurring $>3$ months postoperatively), resulting in substantial cost savings and improved quality of life, especially in high-risk patients. [3, 9, 11] However, because BIS has not been considered the standard BCRL monitoring method, it is not usually covered by health insurance companies despite studies demonstrating reduced chronic BCRL using BIS as well as cost-effectiveness with the technique. [5, 12].

A previous meta-analysis from DiSipio et al. evaluated the incidence of BCRL and risk factors finding that approximately one in five women will develop BCRL post-treatment with increased risk for those undergoing ALND and mastectomy [4]. We therefore conducted a meta-analysis in order to determine the relative reduction in progression to chronic BCRL among BC patients, comparing (a) BIS monitoring as a trigger for early intervention, using the L-Dex U400 device; (b) limb circumference monitoring with tape measure; and (c) the background rate of progression. The primary outcome of interest was annual progression to chronic BCRL in patients experiencing either (a) the background rate of progression, with either no monitoring or monitoring without standardized BCRL circumference or BIS assessments; (b) monitoring with BIS and early intervention; or (c) monitoring with tape measures of limb circumference with or without intervention.

\section{Materials and methods}

\section{Eligibility criteria}

With the intent to provide an update to the previous metaanalysis conducted by DiSipio et al. in 2013, we conducted a systematic literature review to identify studies investigating chronic BCRL occurrence or progression in adult women with breast cancer. [4] In order to be eligible, each peerreviewed study must have been published in English in 2013 or later (up to 2019 when search was performed) and conducted in North America, Europe, or Oceania. Studies were included as background studies if they reported the BCRL rate over any postsurgical time frame in any group of female breast cancer patients, regardless of study design, as the previous meta-analysis did not exclude studies based on monitoring method. Prospective surveillance and retrospective chart review studies were included as circumference or BIS studies if they specifically described using the L-Dex U400 BIS device or the tape measure method, included a presurgical baseline measurement, and reported the BCRL rate over any postoperative time frame. Randomized controlled trials were included in the tape measure or BIS groups if they included a BIS group, a circumference-monitoring group, or both, with a presurgical baseline measurement, in direct comparison to each other or to a control group with no monitoring. All data abstraction, analyses, and interpretation were conducted without the involvement of the sponsor.

\section{Information sources and search strategy}

The systematic literature search was conducted following PRISMA guidelines and focused on the electronic databases PUBMED and CINAHL. [13] In addition, a Google Scholar search was conducted in which the first three pages of results were reviewed to identify potential additional references. Reviewers also screened references cited in recent publications in which the L-Dex U400 device was used to identify additional studies potentially eligible for inclusion.

The literature search made use of the following terms to identify relevant publications without limiting by date: "breast cancer" AND (lymphedema OR lymphoedema OR "lymphatic edema") AND (incidence OR prevalence OR rate); "breast cancer" AND (lymphedema OR lymphoedema OR "lymphatic edema") AND (monitoring OR surveillance); or "breast cancer" AND (lymphedema OR lymphoedema OR "lymphatic edema") AND ("bioelectrical impedance" OR "bioimpedance" OR "bioimpedance 
spectroscopy" OR “BIS” OR “L-Dex” OR “bioimpedance analysis" OR "BIA").

\section{Reference screening}

Two independent reviewers initially screened all study abstracts considered eligible. Exclusions during this stage were based on deviations of methodologies and populations from the predefined criteria, as well as sources other than peer-reviewed journals, and any duplicate references. The reviewers then compared their inclusion decisions for all abstracts. Any discrepancies were resolved through discussion; if a conclusion could not be reached, the decision for inclusion or exclusion was made by a senior author. A reference manager tool, Mendeley, allowed for compilation, screening, and tagging for inclusion/exclusion of the publications was identified from the systematic literature search. At this point, articles published prior to 2013 were excluded so the results would be a true extension of the DiSipio metaanalysis. [4] Next, the two reviewers conducted an independent screening of $10 \%$ of the full-length texts for each study and ensured there was $80 \%$ agreement in their decisions. [14] The each reviewer then reviewed half of the remaining full-text articles. This screening excluded any articles that a full-text reading found to lack BCRL incidence or progression rates, usable counts to determine rates, clearly defined follow-up periods, or identification of the specific device used if a BIS device was part of the methodology, or that included only self-reported lymphedema.

\section{Data abstraction}

Following completion of the full-text review, two reviewers abstracted all elements of interest from the full-length texts. Primary abstraction of articles was performed by ND, with support by AS. All data abstracted were thoroughly checked by the other reviewer to ensure accuracy in abstraction. Any discrepancies throughout the abstraction process were resolved through discussion; if a conclusion could not be reached, decisions were made by a senior author. In addition to basic study information (year of publication, location, design, start and end dates for data collection, study duration, patient inclusion and exclusion criteria, percent of participants lost to follow-up, definition of progression to lymphedema, and lymphedema measurement methods), key data elements for each arm related to patient demographics, treatment, and development of lymphedema were abstracted. These included age, race, and body mass index (BMI) of participants; percent of patients experiencing mastectomy, breast conservation techniques, ALND, sentinel lymph node biopsy (SLNB), taxane chemotherapy, or RNI; the final number of patients in the study arm diagnosed with progression to chronic BCRL (in the case of studies with early intervention (which could be variable interventions including compression sleeve or other therapies), this meant the number diagnosed following intervention, not the number triggering early intervention); and the mean time to progression. To be included in the BIS monitoring group, the studies classified patients with chronic BCRL as having an L-Dex score of ten or greater; to be included in the circumference monitoring group, the studies used the accepted standard of two $\mathrm{cm}$ difference or more. If the studies used non-standard methods, such as volume calculations, they were included within the background group and categorized as monitoring. Studies could contribute data to more than one group if they included multiple arms and separate arms met inclusion criteria for different groups. Monitoring via bioimpedance assessment (BIA) is based on a smaller range of frequencies (or even a single frequency) than BIS and was assigned to the background group.

\section{Statistical analysis and synthesis}

Stata (version 13; StataCorp LLC, College Station, Texas) was used to conduct all analyses. Synthesis of studies reporting rates of chronic BCRL in the absence of monitoring via tape measurement of limb circumference or BIS provided estimates for the background rate of chronic BCRL. Rate of progression to chronic BCRL was then synthesized for studies involving surveillance and early intervention based on BIS or tape measurement. A random-effects model was used in the analysis to account for both clinical and methodological heterogeneity. Known risk factors for BCRL were assessed via subgroup analyses. Sufficient data were available on the proportion of patients undergoing ALND, SLNB, and Mastectomy. Thresholds were selected empirically from the data. Other known risk factors not included due to a lack of data were BMI, taxane chemotherapy, and RNI.

Results are reported without transformation but were square-root transformed to help stabilize variability and confirm that heterogeneity was better controlled. Rates of progression to chronic BCRL were annualized from the data reported by each study, based on the length of reported follow-up. BCRL rates associated with BIS monitoring and with tape measurement were then compared to each other and to background rates. Heterogeneity for all estimates was acceptable (I $[2] \leq 50 \%$ ) when data were square-root transformed, with a few exceptions (Tables 3, 4). In Table 3, the exceptions were overall pooled estimate for circumferencemonitored studies $\left(\mathrm{I}^{2}=61.0 \%\right)$; circumference-monitored studies for $>2$ years $\left(\mathrm{I}^{2}=82.6 \%\right)$; circumference-monitored, prospective studies $\left(\mathrm{I}^{2}=74.6 \%\right)$; and background RCT studies $\left(\mathrm{I}^{2}=61 \cdot 3 \%\right)$. In Table 4 , the exceptions were circumference-monitored for ALND $>50 \%\left(\mathrm{I}^{2}=55.9 \%\right)$, circumference-monitored \& both SLNB analyses (SNLB $\leq 50 \%$ : $\mathrm{I}^{2}=85.0 \%$; SLNB $>50: \mathrm{I}^{2}=54 \cdot 2 \%$ ), background rate 
for ALND $>50 \%\left(\mathrm{I}^{2}=57 \cdot 5 \%\right)$, and background rate for SLNB $\leq 50 \%\left(\mathrm{I}^{2}=65 \cdot 3 \%\right)$.

\section{Results}

A total of 2,259 individual references were identified from the literature searches (Fig. 1). Of these, 1922 (85.1\%) were excluded during the initial review of abstracts and titles for not meeting eligibility criteria. Of the remaining 337 studies which then underwent full-text review, 143 studies were excluded due to being published prior to 2013. Of the remaining 194, an additional 144 articles (74.2\%) were excluded, leaving 50 articles included in the analysis. Figure 1 details reasons for exclusion based on full-text review. Of the 50 studies remaining for inclusion in the meta-analysis, 27 were prospective surveillance designs, 14 were retrospective chart reviews, and nine were RCTs. 35 studies provided estimates of the background rate of progression to BCRL; 11 studies provided estimates for monitoring with tape measurement; and 7 studies provided estimates for monitoring with BIS. Three studies contributed data to more than one arm. [15-17] One study reported an incidence of 0 , which was set to $0 \cdot 5$. This continuity correction is supported in the literature for analyses including only one study with a zero count. [18, 19] Mean or median length of follow-up across studies ranged from one to ten years. Tables 1 and 2 and Supplemental Table S1 summarize characteristics of the studies included; of note differences in the rates of ALND did exist. [8, 15-17, 20-65].

Estimates of average annual incidence varied significantly across studies, from $0 \cdot 2 \%$ to $39 \cdot 4 \%$. Pooled summary estimates of annualized incidence were highest for RCTs and lowest for retrospective studies (Table 3). The pooled estimate for cumulative incidence of BCRL was $12.9 \%$ (95\% CI: $11 \cdot 3-14 \cdot 4), 17.0 \%$ (95\% CI: $10 \cdot 3-23.7)$, and $3.1 \%$ (95\% CI: 1.3-4.9) for background, circumference, and BIS, respectively. The annualized incidence was $4.9 \%(95 \%$ CI: $4 \cdot 3-5 \cdot 5), 7.7 \%$ (95\% CI: 5·6-9.8), and 1.5\% (95\% CI: 0.6-2.4) for background, circumference, and BIS, respectively. Monitoring with BIS was associated with a significantly lower rate of progression to BCRL compared with rates in both background and circumference-monitored populations. Specifically, relative rates of progression in BISmonitored patients were reduced by $69 \%$ compared to background rates and $81 \%$ compared to circumference-monitored populations based on overall pooled rates. This significant reduction in progression to BCRL among BIS-monitored patients was observed regardless of study duration or study type, with the exception of comparison to circumferencemonitored patients in RCT studies. All differences in rates were statistically significant at $p<0 \cdot 05$, with a few exceptions as presented in Table 3 (Fig. 2a-c).
Forty-five studies provided data on the percentage of patients receiving ALND. Overall rates of clinical BCRL were higher in studies with a majority ( $>50 \%)$ of patients undergoing ALND (Table 4). This difference was observed for all three study arms, although it was most pronounced for BIS-monitored patients (Fig. 3a-c). BIS-monitored patients had a 56\% reduced rate of progression compared to circumference-monitored patients in studies with $>50 \%$ ALND, and an $84 \%$ reduced rate of progression compared to circumference-monitored patients in studies with $\leq 50 \%$ ALND. BIS-monitored patients had a $68 \%$ reduced rate of progression compared to background studies in patients with $\leq 50 \%$ ALND. Forty-three studies provided data on the percentage of patients receiving mastectomy. Rates of clinical BCRL were lower in BIS and circumference-monitored studies with a high rate $(>40 \%)$ of patients receiving mastectomy compared to those with $\leq 40 \%$ of patients, but not for the background group. BIS-monitored patients had a $79 \%$ reduced rate of progression compared to circumferencemonitored patients in studies with $>40 \%$ mastectomy, and a $7 \%$ reduced rate of progression compared to circumferencemonitored patients in studies with $\mathrm{a} \leq 40 \%$ mastectomy (not statistically significant) (Table 4). BIS-monitored patients had a $75 \%$ reduced rate of progression compared to background rates for patients with $>40 \%$ mastectomy.

With respect to the potential for follow-up bias, the rates of clinical BCRL differed significantly for studies with average or median follow-up of $\leq 2$ years versus those with $>2$ years of follow-up (Table 3 ). The pooled rate of BCRL in studies with follow-up of $\leq 2$ years was more than double that of longer studies for background and BIS studies (Fig. 2a, b) but the difference was not as pronounced in tape measurement studies (Fig. 2c).

\section{Discussion}

The results of this meta-analysis demonstrate that patients followed with BIS surveillance were significantly less likely to develop chronic BCRL annually (and overall) as compared to the background rate and tape measurement. This difference was not only statistically significant but clinically as well; the annualized BCRL incidence rate was $69 \%$ (3.4\% absolute difference) lower than the observed background rate and $81 \%$ (6.2\% absolute difference) lower than that observed with tape measurement. Importantly, patients monitored with BIS had a lower annualized incidence even in high-risk populations ( $>40 \%$ mastectomy and $>50 \%$ ALND). Similarly, a clinically significant difference in the cumulative BCRL incidence rate was noted with a 9.8\% absolute reduction compared to observed background rate and a $13.9 \%$ absolute reduction as compared with tape measurement. While there were differences in rates of ALND 
Fig. 1 CONSORT Diagram

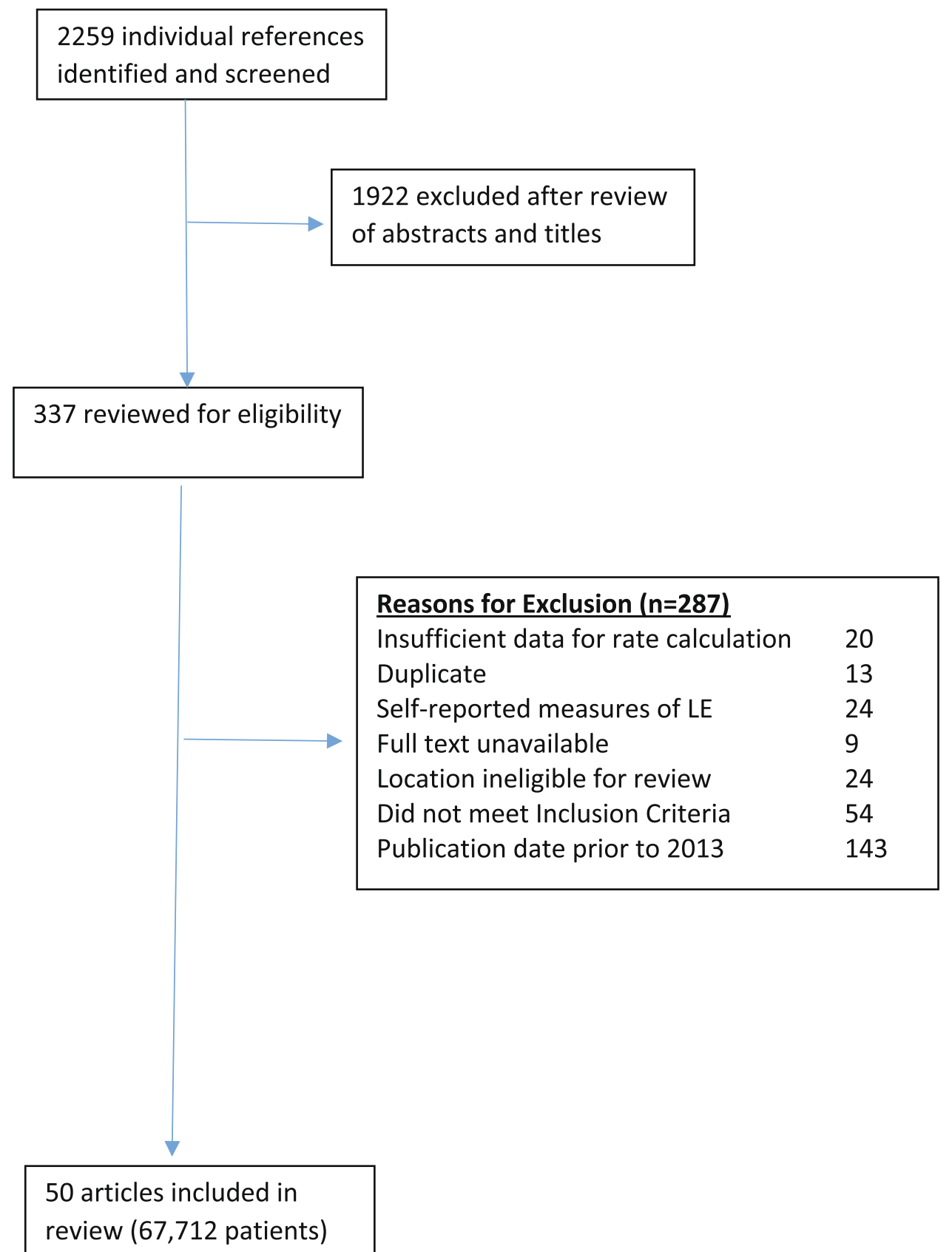

\begin{tabular}{|c|c|}
\hline \multicolumn{2}{|c|}{ Included Articles $(n=50)$} \\
\hline Prospective & 27 (10,634 patients) \\
\hline $\mathrm{RCT}$ & 9 (54,640 patients) \\
\hline Retrospective & 14 (2,438 patients) \\
\hline
\end{tabular}

RCT-Randomized control trial 
Table 1 Patient population characteristics

\begin{tabular}{|c|c|c|c|c|c|c|c|c|}
\hline Study type & $\begin{array}{l}\text { Studies } \\
\text { included in } \\
\text { analysis }\end{array}$ & $\begin{array}{l}\text { Total patients } \\
(n)\end{array}$ & $\begin{array}{l}\text { Mastectomy } \\
(\%)\end{array}$ & $\begin{array}{l}\text { Breast conser- } \\
\text { vation }(\%)\end{array}$ & ALND (\%) & SLNB (\%) & $\begin{array}{l}\text { Taxane } \\
\text { chemotherapy } \\
(\%)\end{array}$ & RNI (\%) \\
\hline $\begin{array}{l}\text { All Back- } \\
\text { ground } \\
\text { Studies }\end{array}$ & 35 & 57,944 & $20,472(35 \%)$ & $36,631(63 \%)$ & $16,888(29 \%)$ & $30,754(53 \%)$ & $\begin{array}{c}1,502 \text { of } 5,398 \\
\text { patients } \\
(27 \%)^{\mathrm{b}}\end{array}$ & $\begin{array}{l}2,607 \text { of } 10,184 \\
\text { patients } \\
(25 \%)^{b}\end{array}$ \\
\hline $\begin{array}{l}\text { Background } \\
\text { (no monitor- } \\
\text { ing studies } \\
\text { only) }\end{array}$ & 11 & 48,833 & $18,392(37 \%)$ & $30,246(61 \%)$ & $12,649(25 \%)$ & $26,058(53 \%)$ & $\begin{array}{c}533 \text { of } 2,216 \\
\text { patients } \\
(24 \%)^{\mathrm{b}}\end{array}$ & $\begin{array}{c}503 \text { of } 2,680 \\
\text { patients } \\
(18 \%)^{\mathrm{b}}\end{array}$ \\
\hline BIS Studies & 7 & 1,924 & $\begin{array}{c}623 \text { of } 1,165 \\
\text { patients } \\
(53 \%)^{\mathrm{b}}\end{array}$ & $\begin{array}{c}541 \text { of } 1,165 \\
\text { patients } \\
(46 \%) \dagger\end{array}$ & $547(28 \%)$ & $1125(58 \%)$ & $\begin{array}{c}314 \text { of } 948 \\
\text { patients } \\
(33 \%)^{b}\end{array}$ & $\begin{array}{c}182 \text { of } 985 \\
\text { patients } \\
(18 \%)^{b}\end{array}$ \\
\hline $\begin{array}{l}\text { Circumference } \\
\text { Studies }\end{array}$ & 11 & 8,403 & $\begin{array}{l}5,362 \text { of } 5,843 \\
\text { patients } \\
(91 \%)^{\mathrm{b}}\end{array}$ & $736(8 \%)$ & $6,213(73 \%)$ & $2019(24 \%)$ & $\begin{array}{l}32 \text { of } 71 \\
\text { patients } \\
(46 \%)^{b}\end{array}$ & $\begin{array}{c}139 \text { of } 180 \\
\text { patients } \\
(77 \%)^{\mathrm{b}}\end{array}$ \\
\hline All Types ${ }^{\mathrm{a}}$ & 50 & 67,712 & $26,436(39 \%)$ & $37,858(55 \%)$ & $23,134(34 \%)$ & $33,845(49 \%)$ & $\begin{array}{c}1,817 \text { of } 6,383 \\
\text { patients } \\
(28 \%)^{\mathrm{b}}\end{array}$ & $\begin{array}{l}2,219 \text { of } 12,217 \\
\text { patients } \\
(18 \%)^{b}\end{array}$ \\
\hline
\end{tabular}

${ }^{\mathrm{a}}$ Total number of patients across all study arms. Please note that Blaney, Armer, and Ridner have patients contributing to multiple arms

${ }^{\mathrm{b}}$ Very few studies contributed. Used only the total number of patients for contributing

Note: ALND Axillary Lymph Node Dissection, SLNB Sentinel Lymph Node Biopsy, RNI Regional Node Irradiation

between populations, when comparing studies with $>50 \%$ of patients undergoing ALND (Table 4), the benefits of BIS were confirmed (Annualized Incidence $6.8 \%$ vs. $15.4 \%$ with circumference, comparative ratio 0.44 ). It is important to recognize that screening techniques such as BIS do not directly reduce rates of BCRL; rather, these findings support that BIS is able to identify changes in fluid content earlier within the patient's limb prior to the development of BCRL, and therefore, the benefit of BIS monitoring is to trigger early intervention in breast cancer patients at risk for chronic BCRL. This earlier diagnosis and intervention along with informing patients likely contribute to the reduction in BCRL allowing for the reversal of the increased fluid volume preventing chronic BCRL which is of substantial clinical importance. [12].

Our results are consistent with previous studies. This study builds on and supports the meta-analysis conducted by DiSipio et al. [4] The cumulative incidence observed in background rate studies, $12.9 \%$ (95\% CI 11.3-14.4), is smaller but in a similar range to the cumulative incidence observed by DiSipio et al. (16.6\%, 95\% CI 13.6-20.2) and is likely consistent with changes in clinical practice over time; a higher rate of annual and cumulative BCRL was seen with circumference as compared to background and this may reflect that, consistent with DiSipio et al., all studies that used non-standard methods (ex. perometry, volume calculation) were included in the background group. Subgroup analyses were also consistent with prior research in identifying ALND as a risk factor for BCRL. Mastectomy as a risk factor was not confirmed in the background rate pooled estimates, although annualized incidence was higher in studies with more than $40 \%$ of patients undergoing mastectomy; this may reflect the increasing use of mastectomy with SLNB (and not ALND) as compared to previous studies. However, for both BIS and tape measurement monitoring studies, the annualized rate of BCRL was lower when the rate of mastectomy was higher (Table 4).

BIS monitoring enables early detection of changes in fluid in affected limbs, particularly in high-risk patient subgroups; additionally, despite potential concerns regarding challenges with implementation, studies have demonstrated the ability implementing this into a standard practice with clinical guidelines available as well $[66,67]$. Early detection can be used to trigger interventions, typically consisting of some combination of compression garments, massage, and physical therapy, to prevent development of chronic BCRL. Such prevention measures improve patient quality of life and reduce the public health burden of chronic BCRL [1, 6 , 7, 9]. Compared to no monitoring, BIS-monitored studies had an overall reduced chronic BCRL relative rate of 59\%. Compared to tape measurement of circumference, BIS-monitored studies had a reduced relative rate of over $80 \%$. These results provide further evidence in favor of BIS in preventing progression to BCRL in comparison to currently accepted methods of monitoring, possibly due to higher sensitivity of BIS to subclinical volume changes $[5,8,10]$. There is now ample evidence that active monitoring of BCRL significantly reduces the risk of progression to BCRL. While 


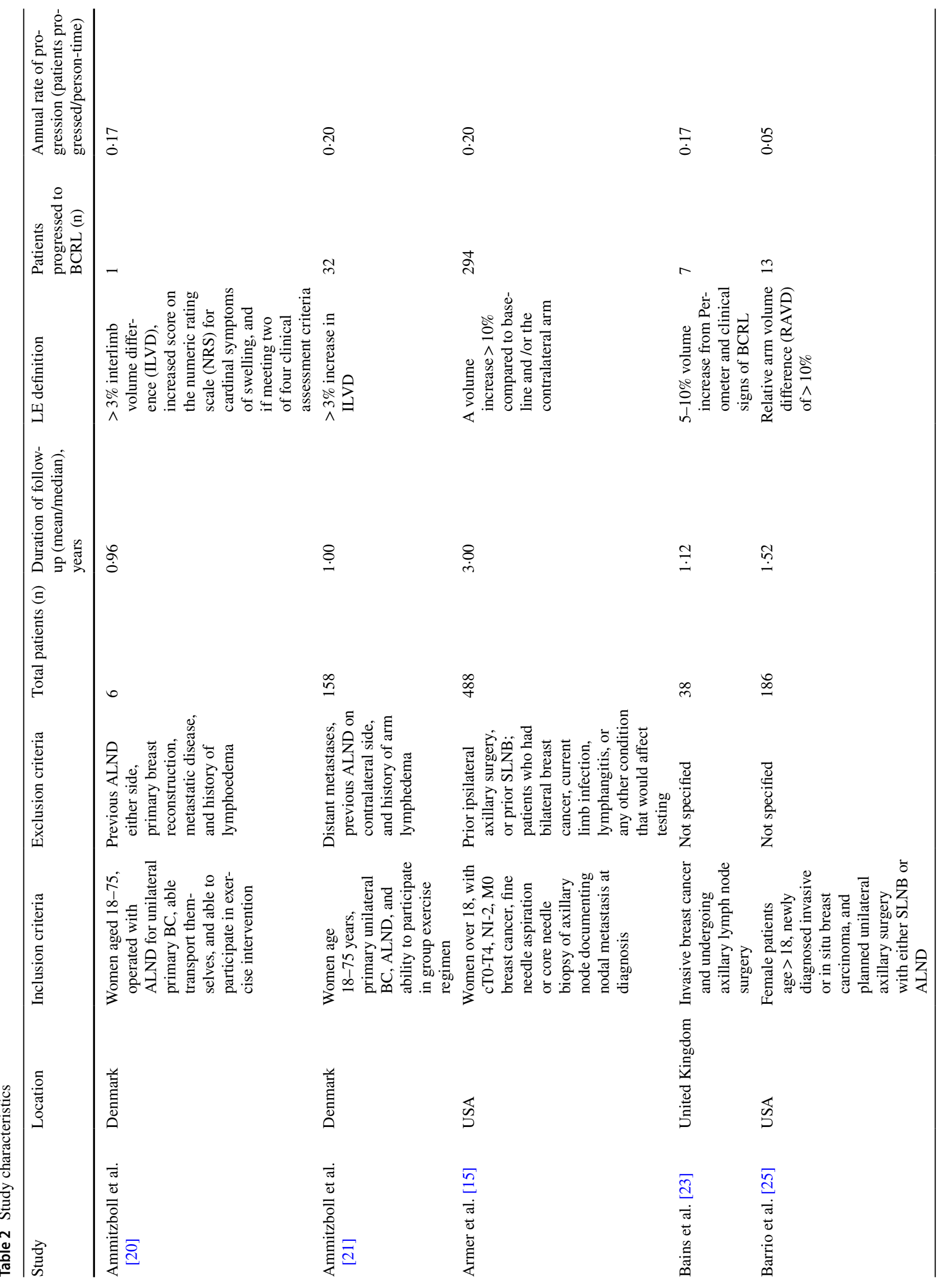




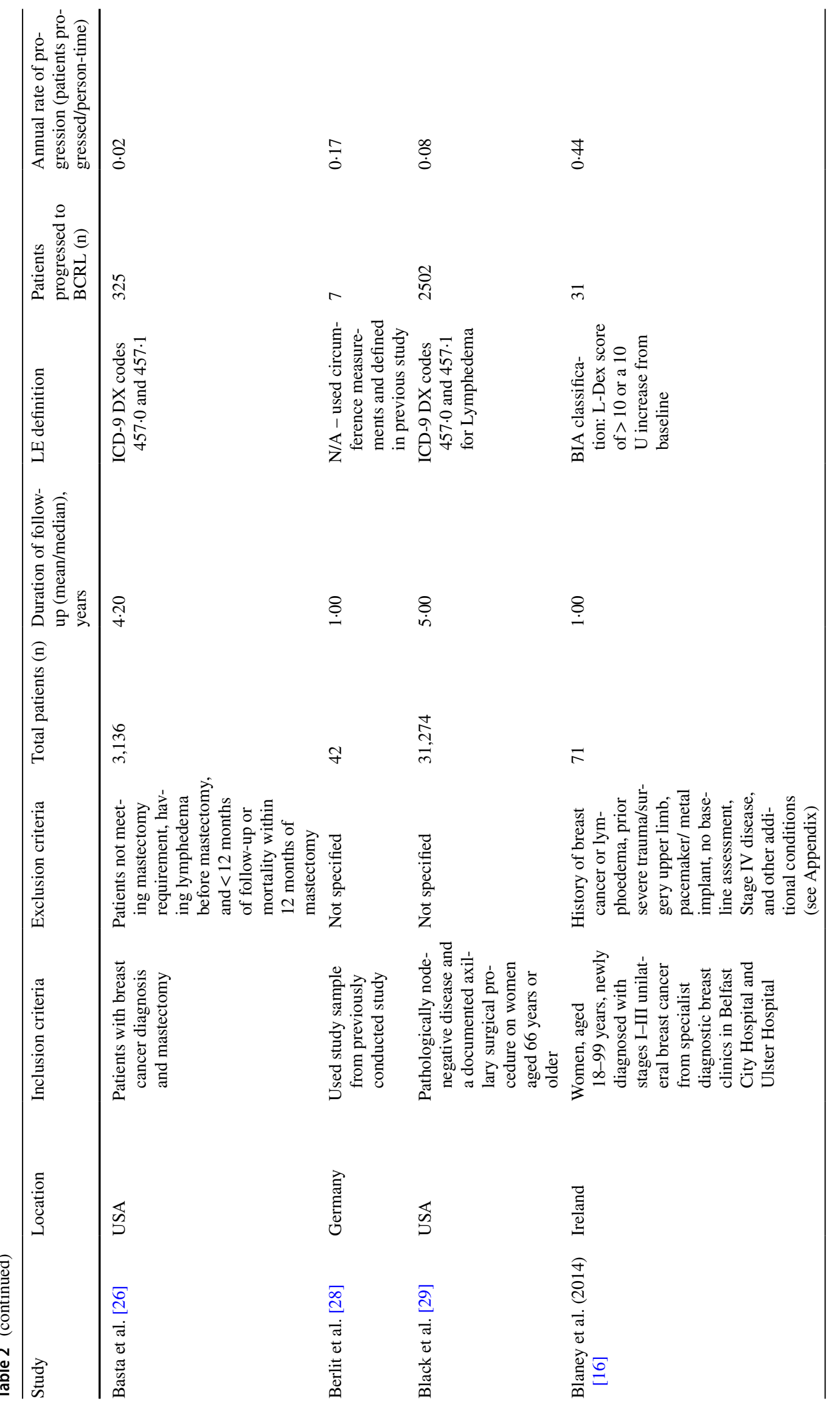




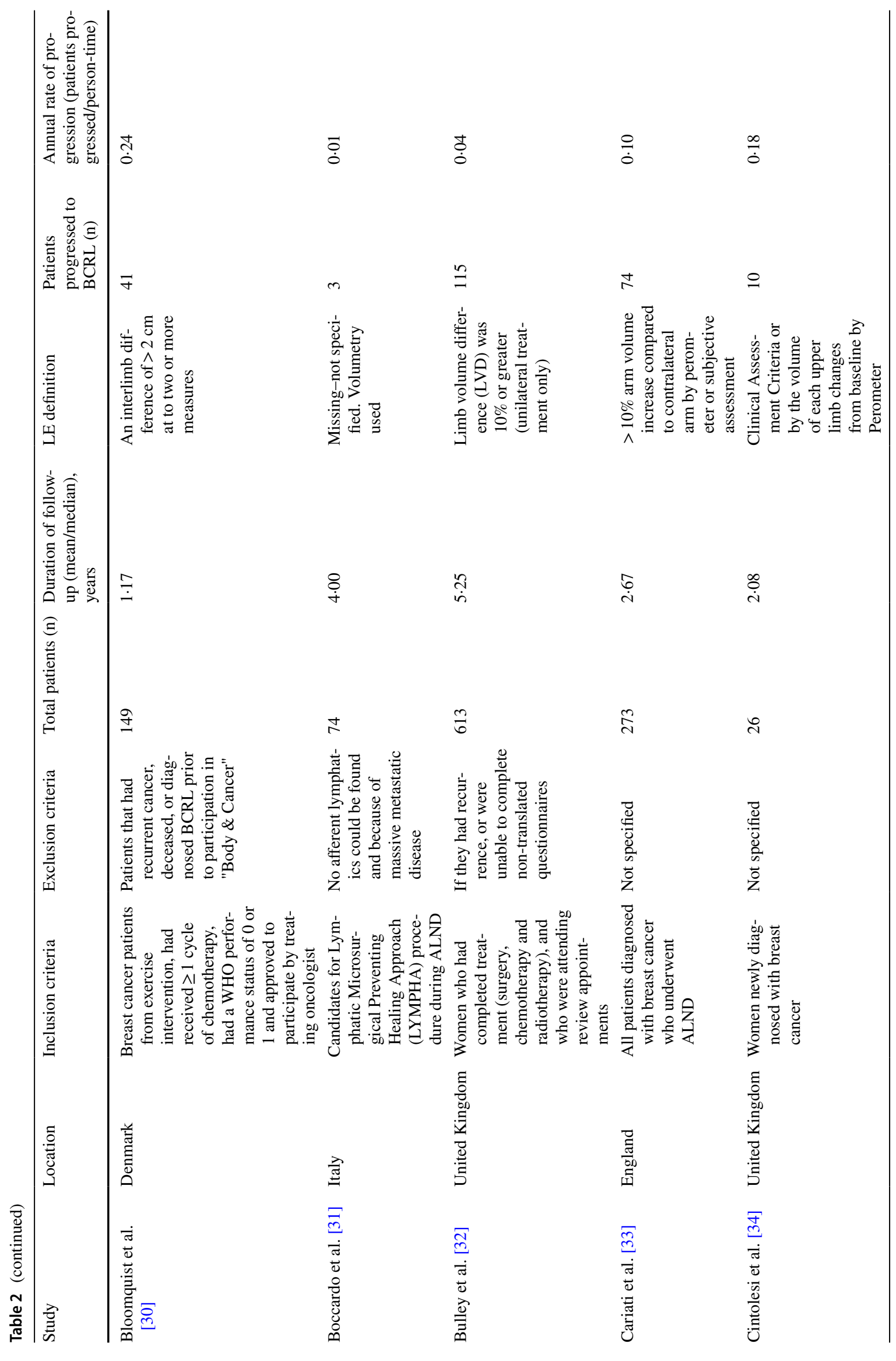




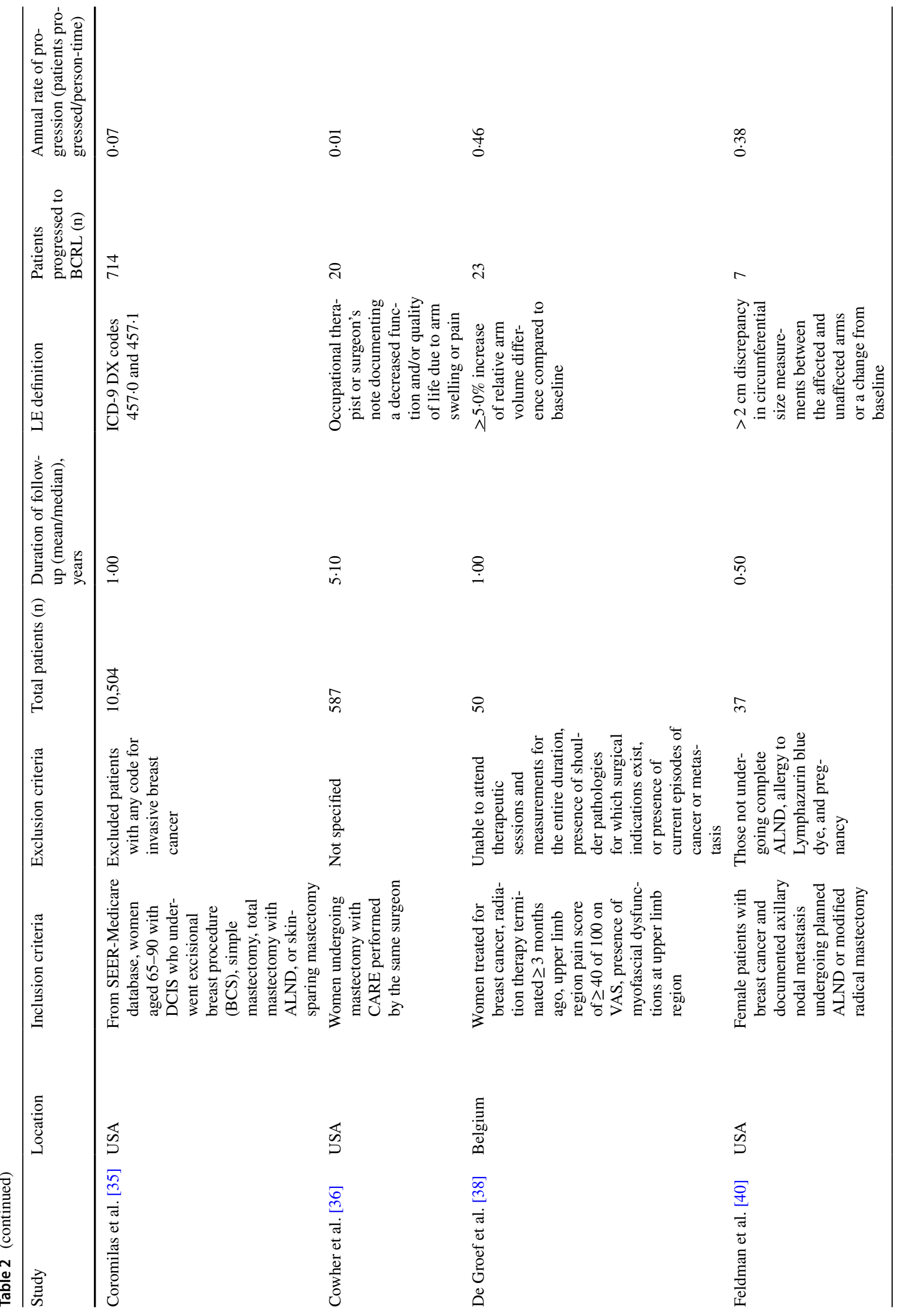




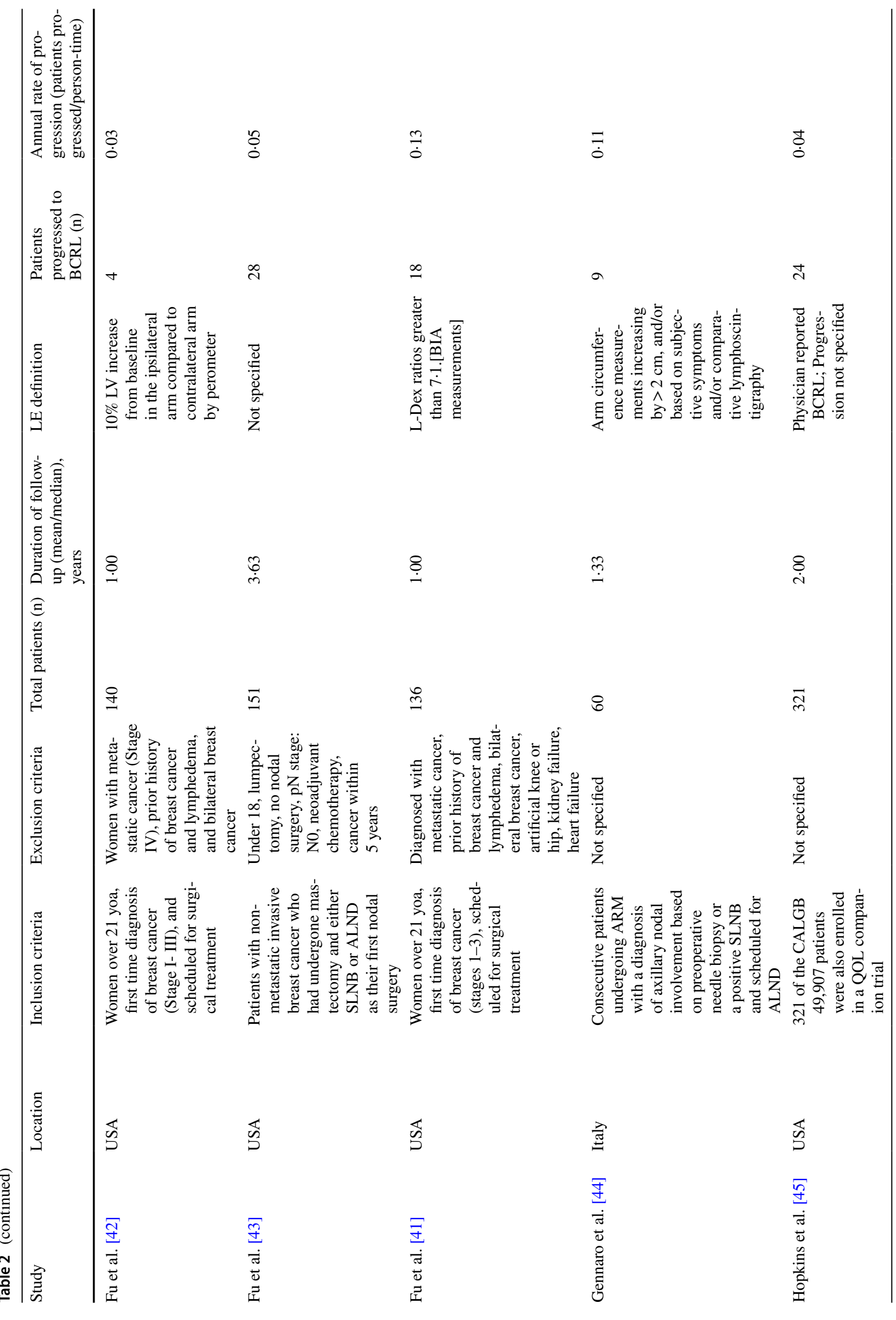




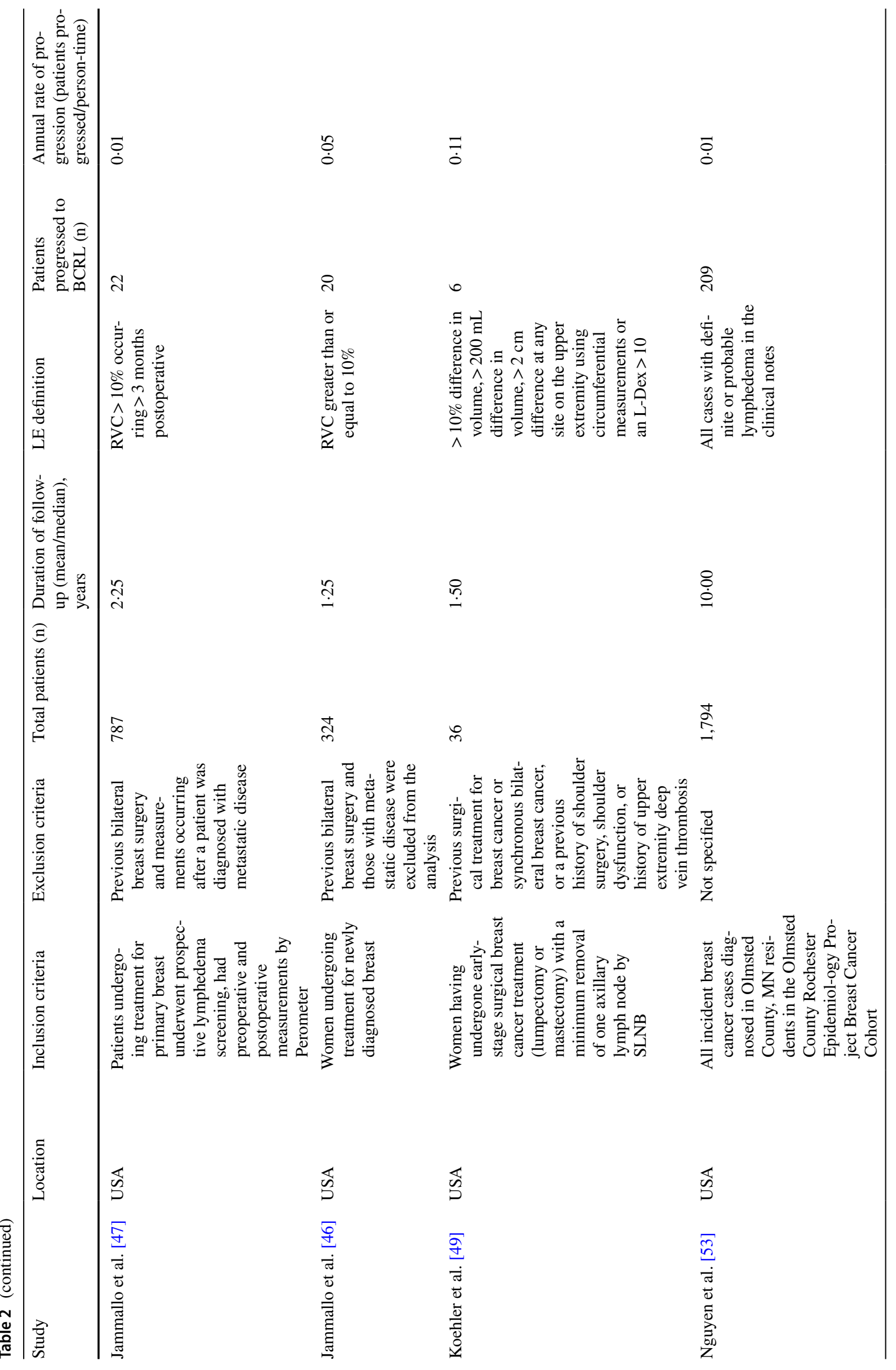




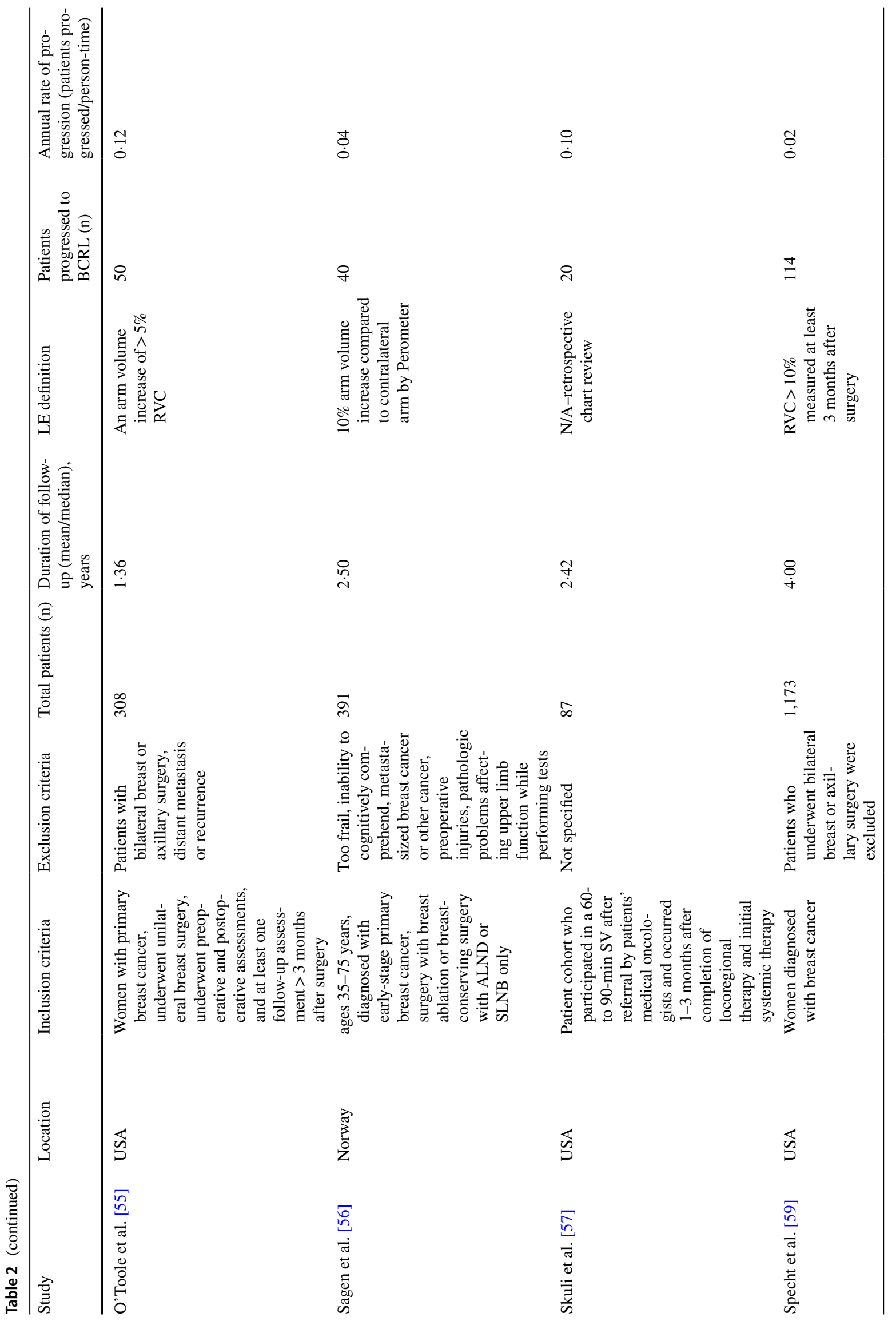




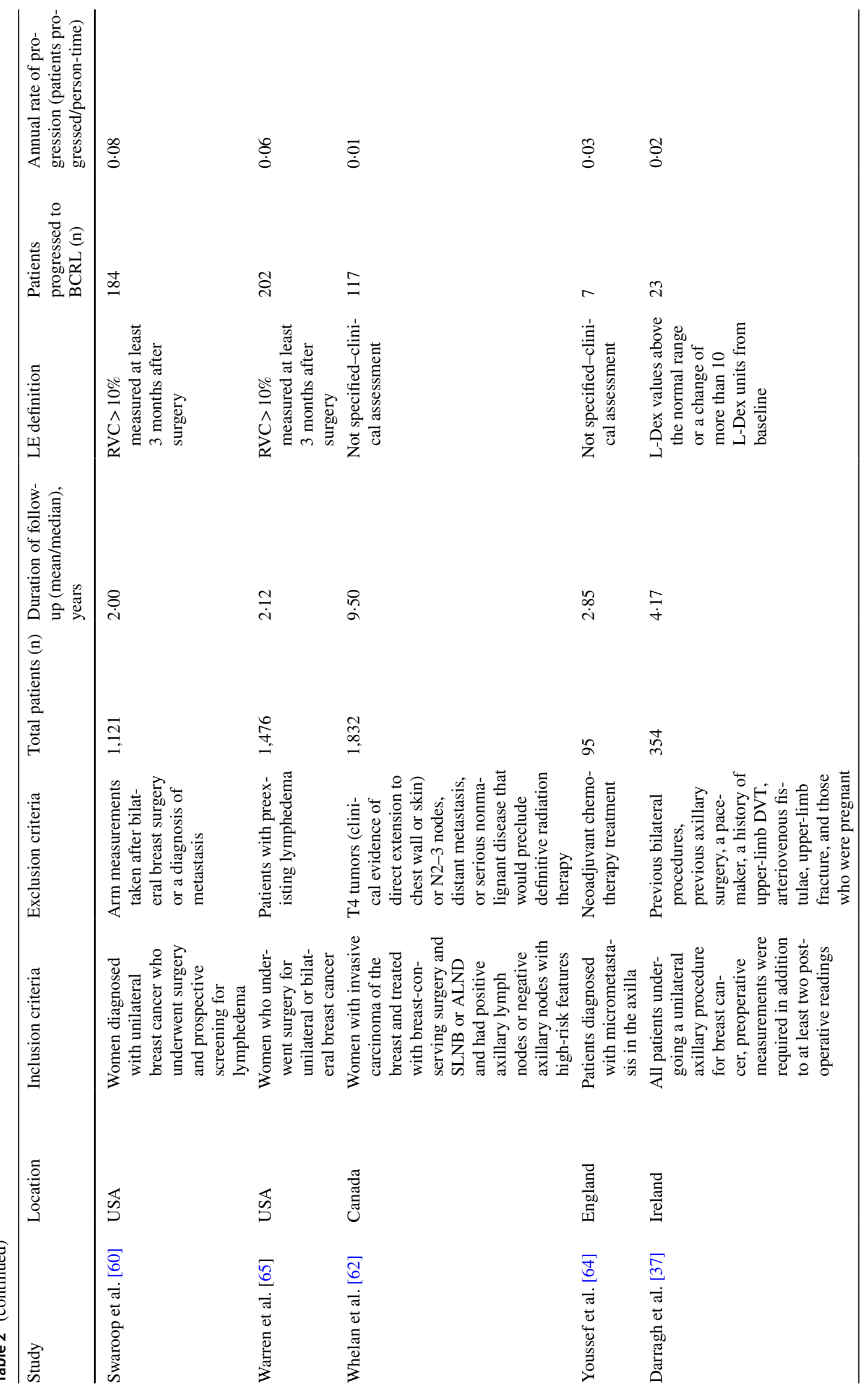




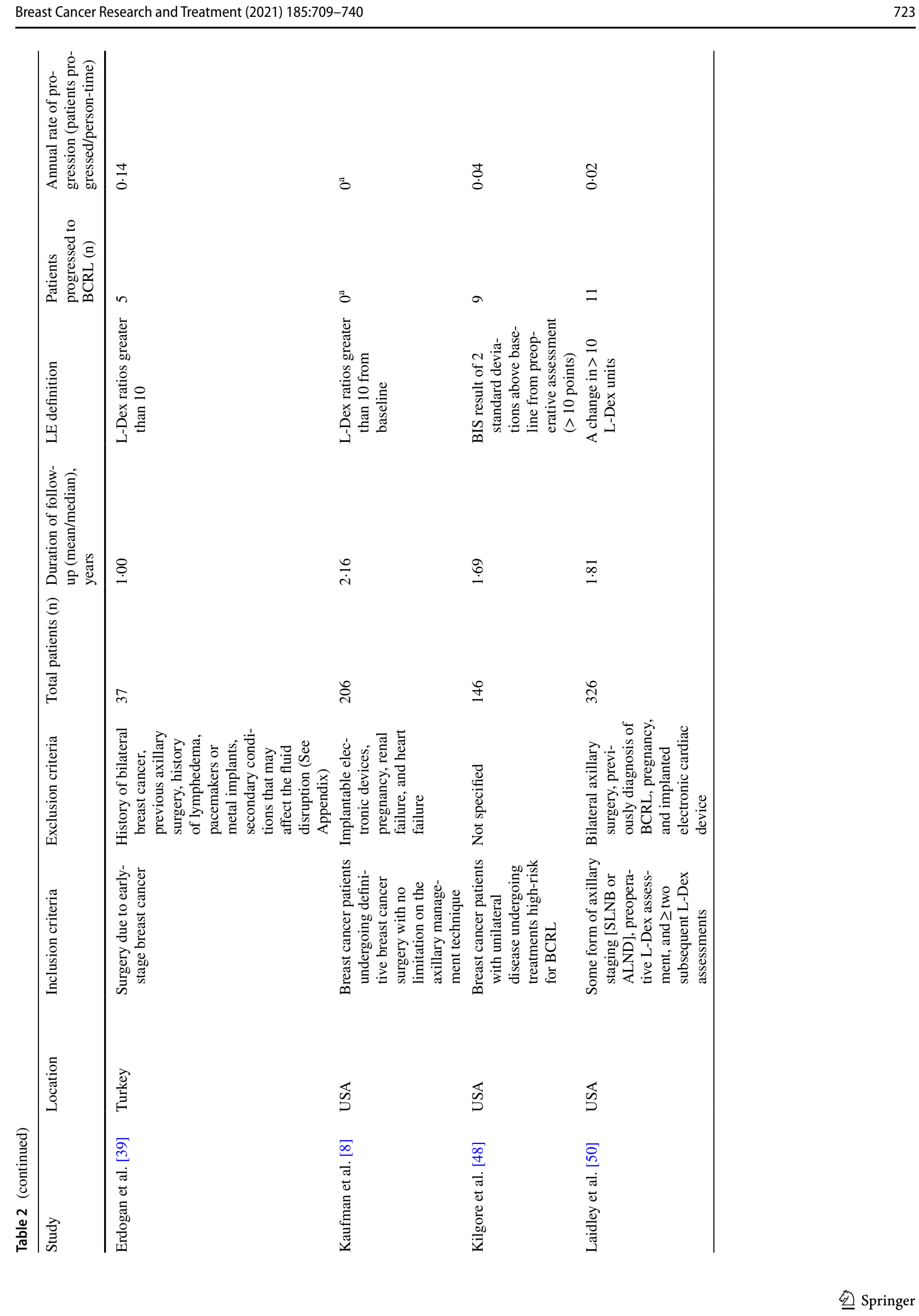




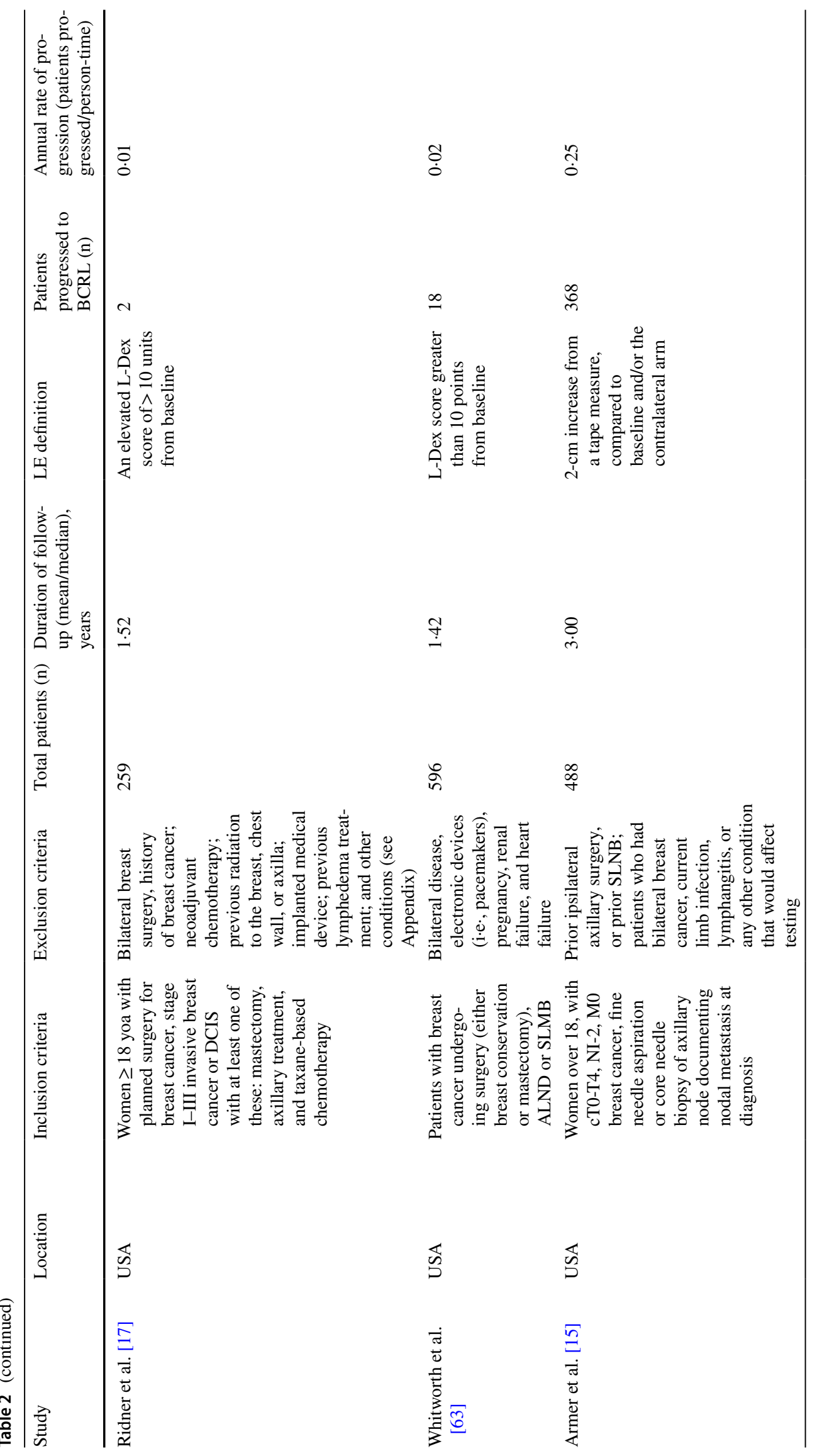




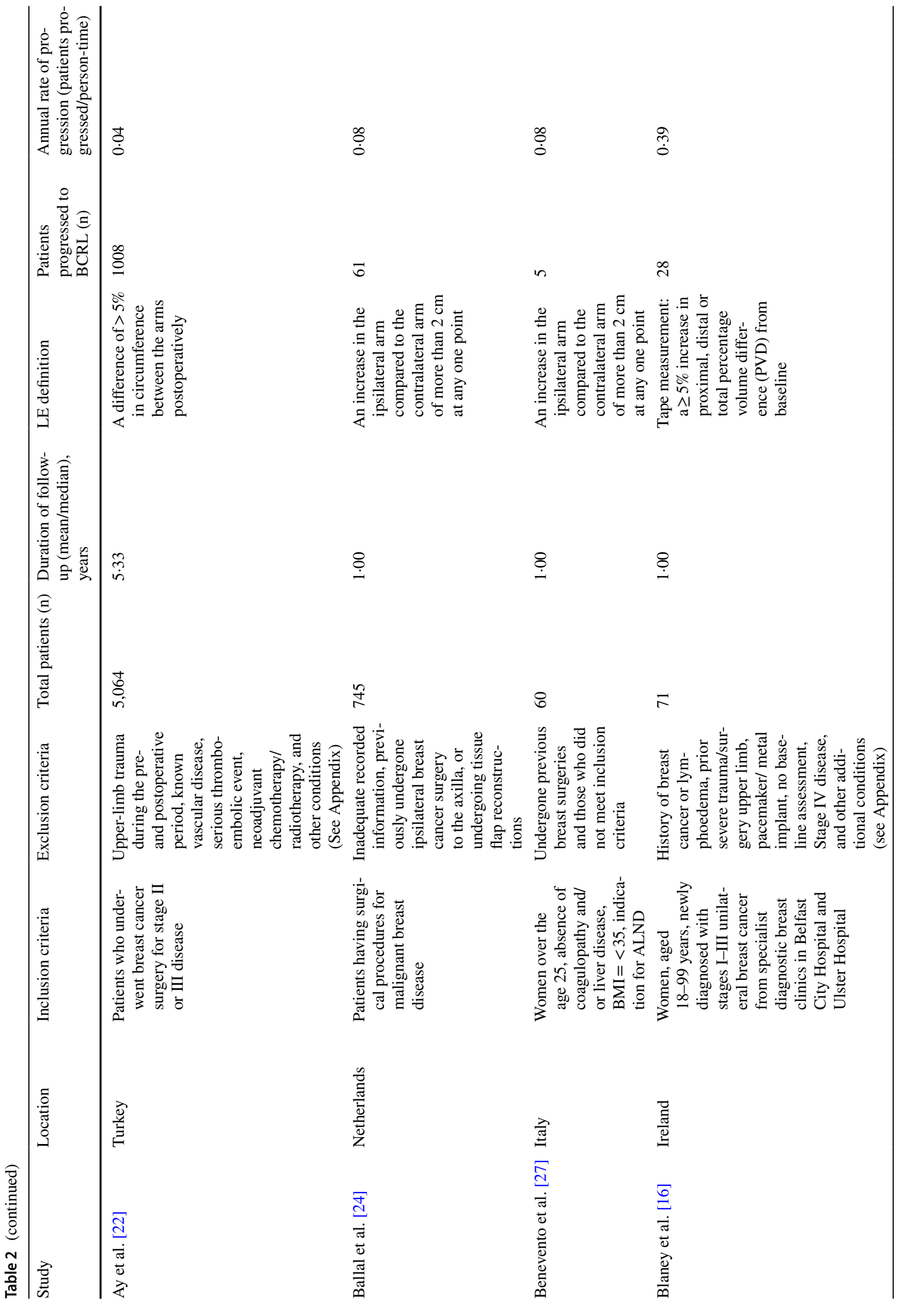




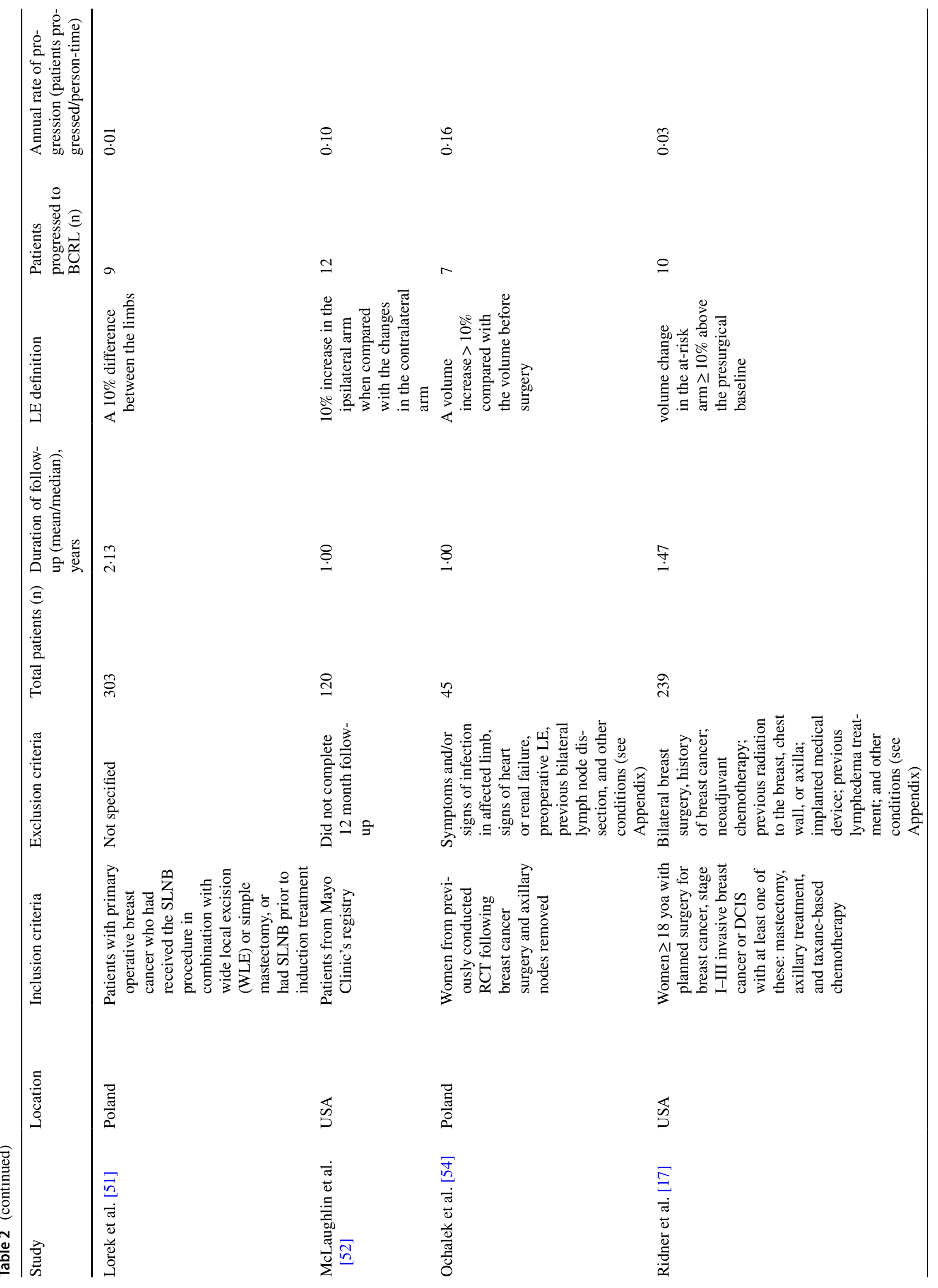




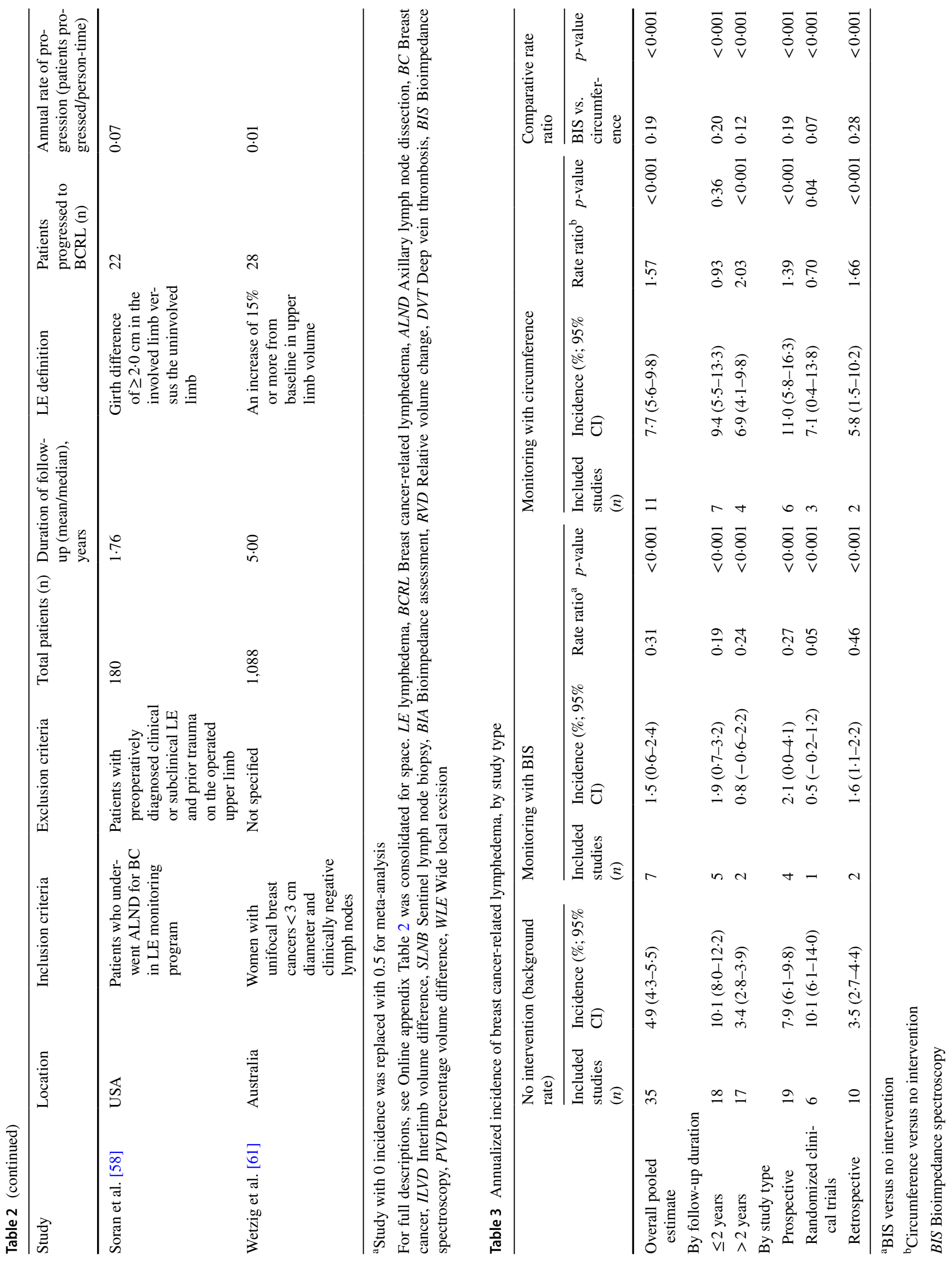




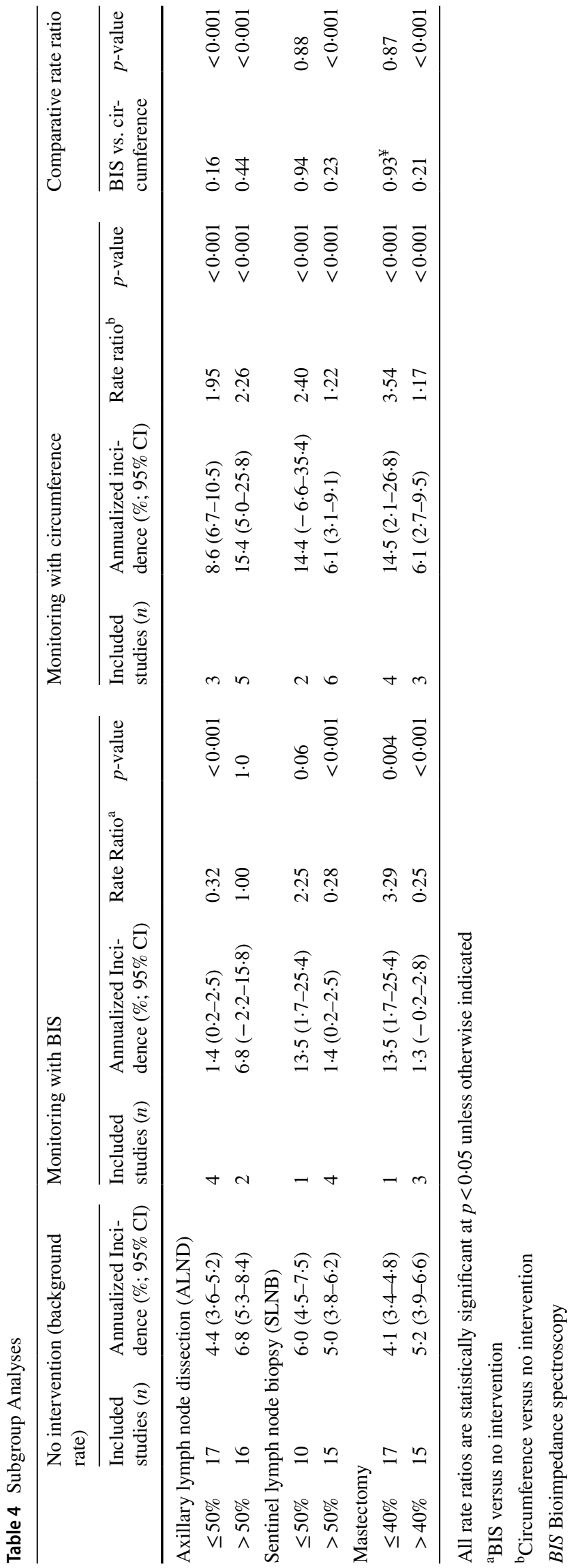

this study compared the effectiveness of monitoring with BIS versus tape measurement for the development of BCRL, future studies should compare BIS to other accepted surveillance methods individually in a prospective study design evaluating high-risk patients. Additionally, recent data and the PREVENT trial have reduced the change initiating a trigger for intervention from 10 to 6.5 , potentially further increasing the sensitivity of BIS to detect subclinical BCRL $[17,68]$.

A key strength of this study is the robust statistical analyses performed. Multiple risk factors of interest were examined for increased risk of BCRL. However, several important limitations must be noted. First, there were relatively few studies $(n=7)$ that used BIS to monitor progression to chronic BCRL. Second, only $28 \%$ of BIS patients had ALND, versus $73 \%$ of circumference patients, suggesting the latter group was at disproportionately greater risk of BCRL. Third, data on patient BMI in many studies were either not available or were not presented continuously. Fourth, most studies did not provide data specifically on taxane-based chemotherapy or RNI (radiation fields including axilla vs axilla + supraclavicular vs. supraclavicular alone), which are also risk factors for BCRL. It would have been advantageous to include subgroup analyses on BMI, taxane-base chemotherapy, and RNI, as they are known to increase patient's risk for BCRL. Definitions of BCRL varied across studies. However, there are no standard clinical cut-points for many of these measures other than BIS [17]. For the BIS studies, in particular, there was greater consistency, with BCRL defined as an increase of 10 units or more in L-Dex scores. Finally, the background group was heterogeneous, though consistent with the previous meta-analysis [4]. A sensitivity analysis was conducted on the background studies to evaluate the BCRL rates for studies with no active monitoring in comparison to other commonly performed monitoring methods (e.g., water displacement) that were included in the background. With no monitoring $(n=11)$, the annualized incidence rate for BCRL was $3.7 \%$. Background studies with other methods of monitoring $(n=24)$ had an annualized incidence rate of $7.6 \%$. This difference indicates the possibility of detection bias when evaluating the low incidence rate of the patients in the no monitoring group. Without active monitoring, it is highly possible for 


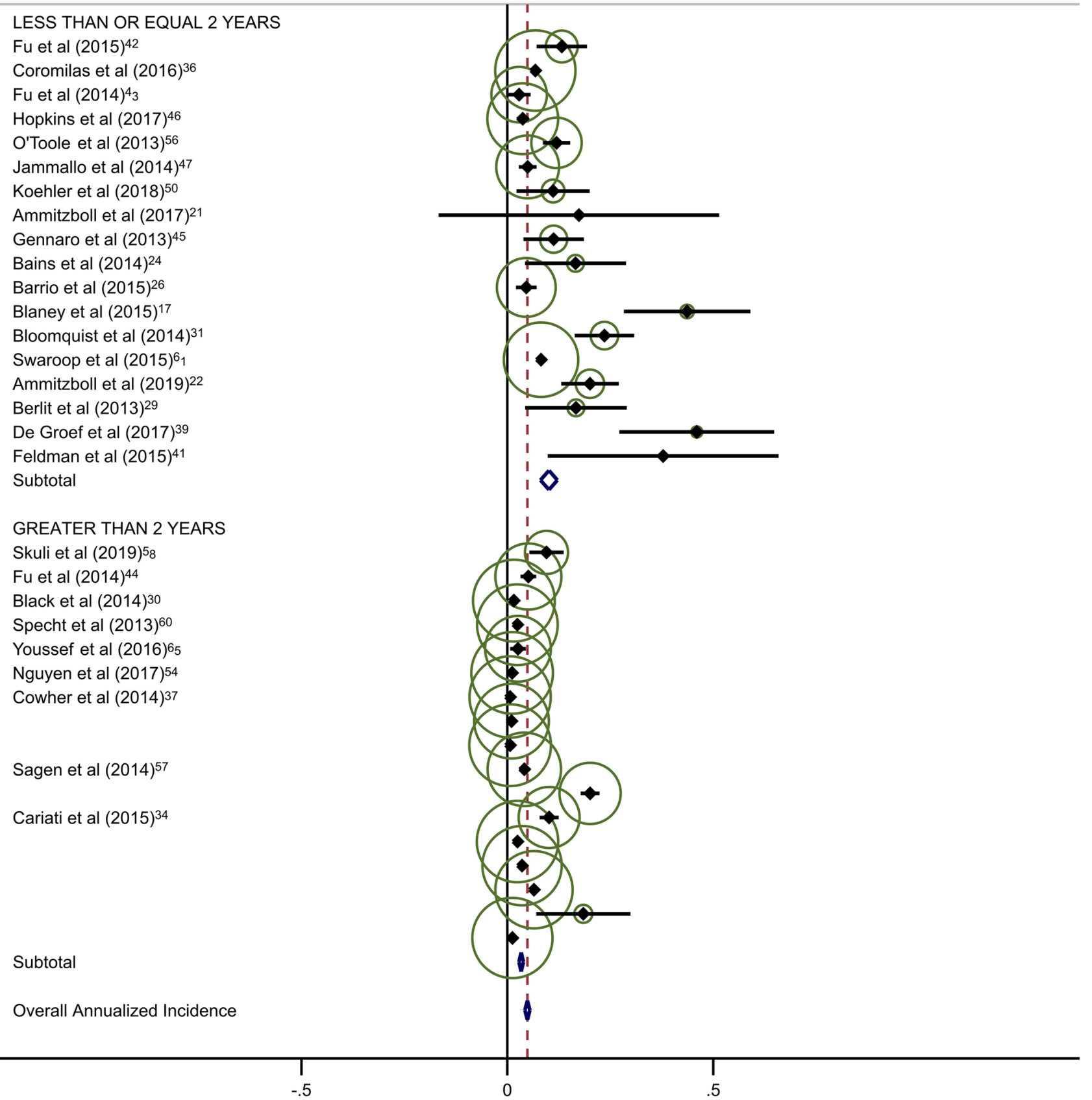

Fig. 2 a Background studies with 2 year cut point. b BIS studies with 2 year cut point. $\mathbf{c}$ Circumference studies with 2 year cut point. Each study is represented by its estimated annualized incidence. The red dotted line is the overall pooled estimated annualized incidence. The light green circles represent the weight for each study to calculate the overall annualized incidence rate and are from the random-effects analysis. The diamond shapes are the variances for each cut point as well as the overall study variance 
Study ID

ES $(95 \% \mathrm{Cl})$

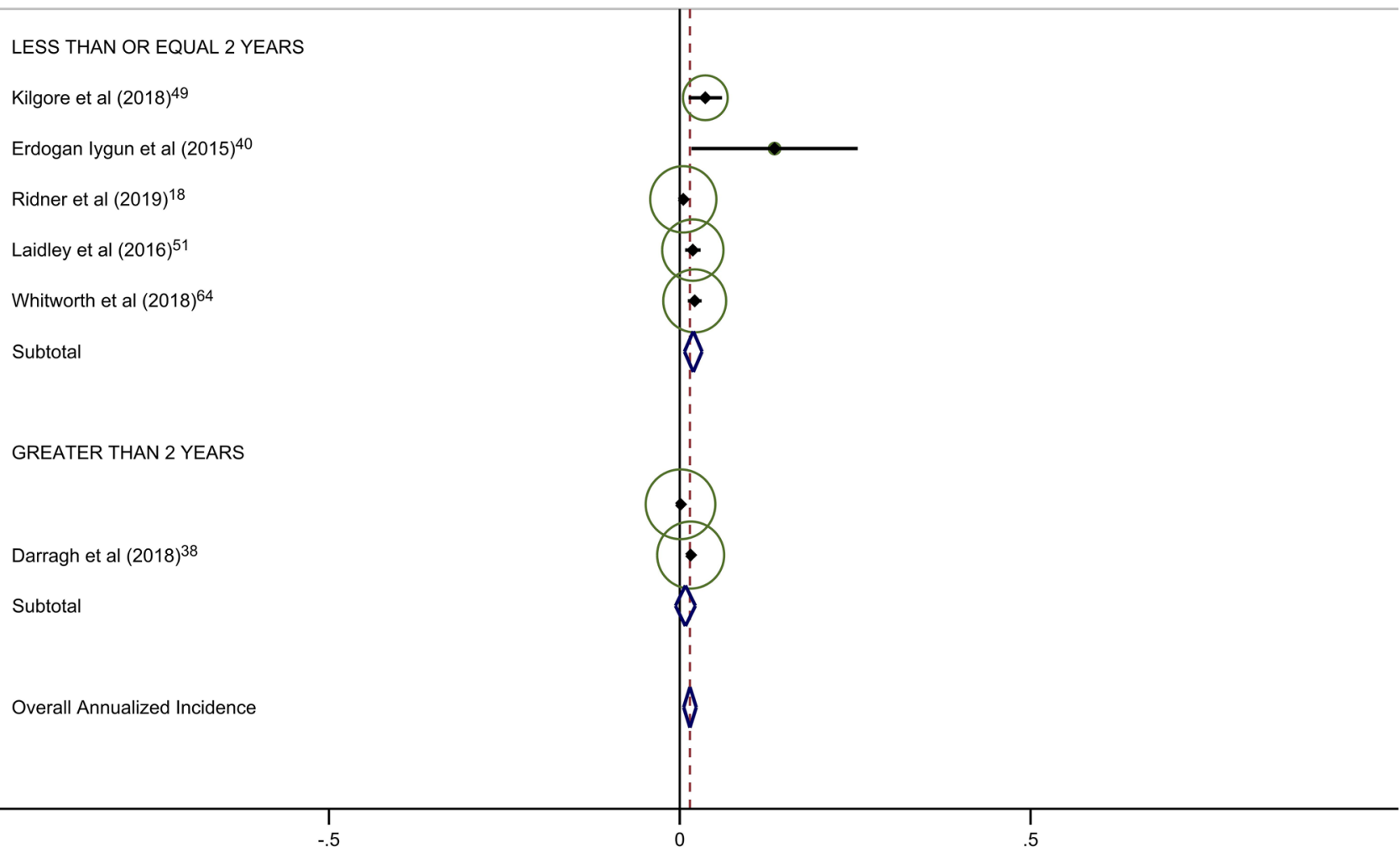

Fig. 2 (continued) 
ES $(95 \% \mathrm{Cl})$

\section{LESS THAN OR EQUAL 2 YEARS}

McLaughlin et al (2013)53

Soran et al (2016) 59

Ballal et al (2018) ${ }^{25}$

Benevento et al (2014) 28

Ridner et al (2019) ${ }^{18}$

Ochalek et al (2017) 55

Blaney et al (2015) ${ }^{17}$

Subtotal

GREATER THAN 2 YEARS

Wetzig et al $(2017)^{62}$

Armer et al (2019) ${ }^{16}$

Lorek et al (2019) 52

Overall Annualized Incidence

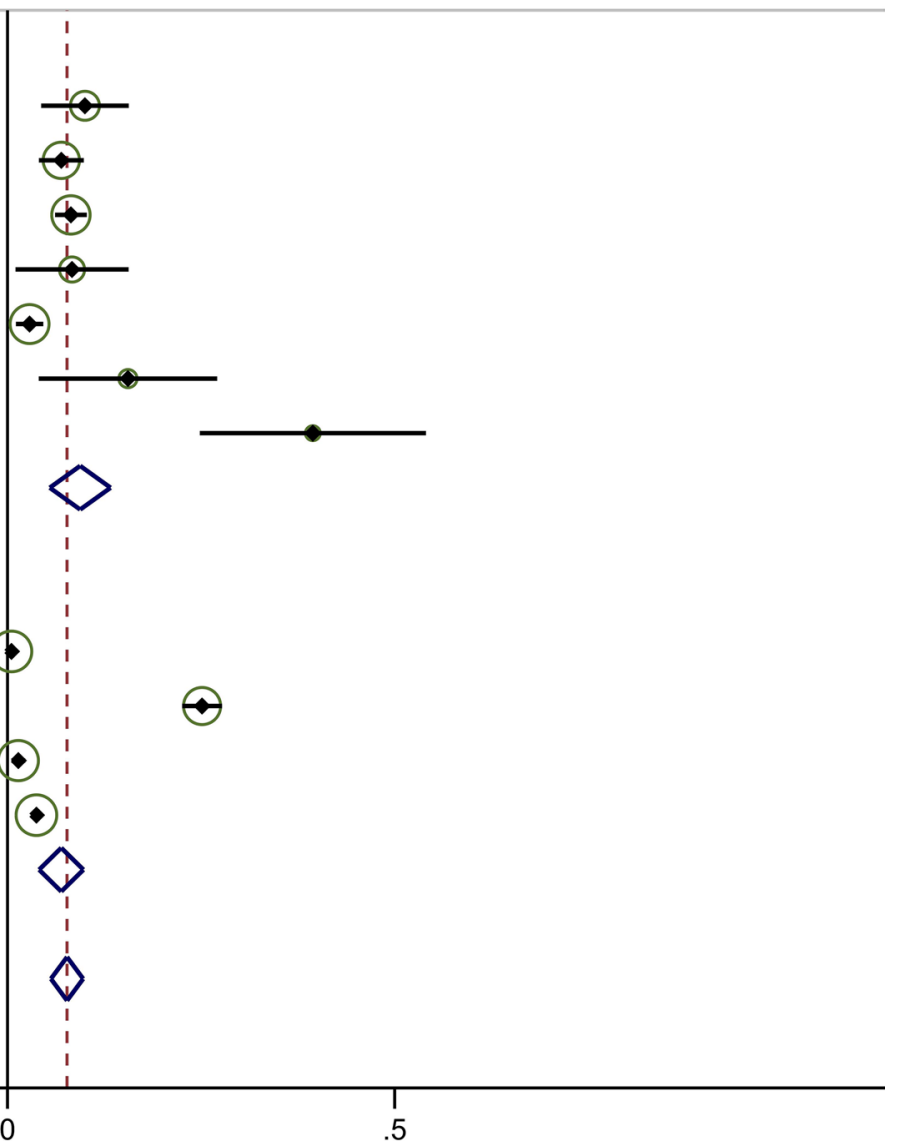

Fig. 2 (continued) 
GREATER THAN 50\%

Fu et al $(2014)^{43}$

Black et al (2014) 30

O'Toole et al (2013)56

Jammallo et al (2014)47

Koehler et al (2018)50

Specht et al (2013)60

Youssef et al (2016)65

Gennaro et al (2013)45

Barrio et al (2015) ${ }^{26}$

Blaney et al (2015)17

Swaroop et al (2015)61

Berlit et al (2013) ${ }^{29}$

Bulley et al (2014) ${ }^{33}$

\section{Subtotal}

LESS THAN OR EQUAL 50\%

Coromilas et al (2016) ${ }^{36}$

Fu et al (2014) $)^{44}$

Hopkins et al (2017) $)^{46}$

Nguyen et al (2017) 54

Ammitzboll et al (2019)22

Armer et al (2019) ${ }^{16}$

Cintolesi et al (2016) ${ }^{35}$

Subtotal

Overall Annualized Incidence

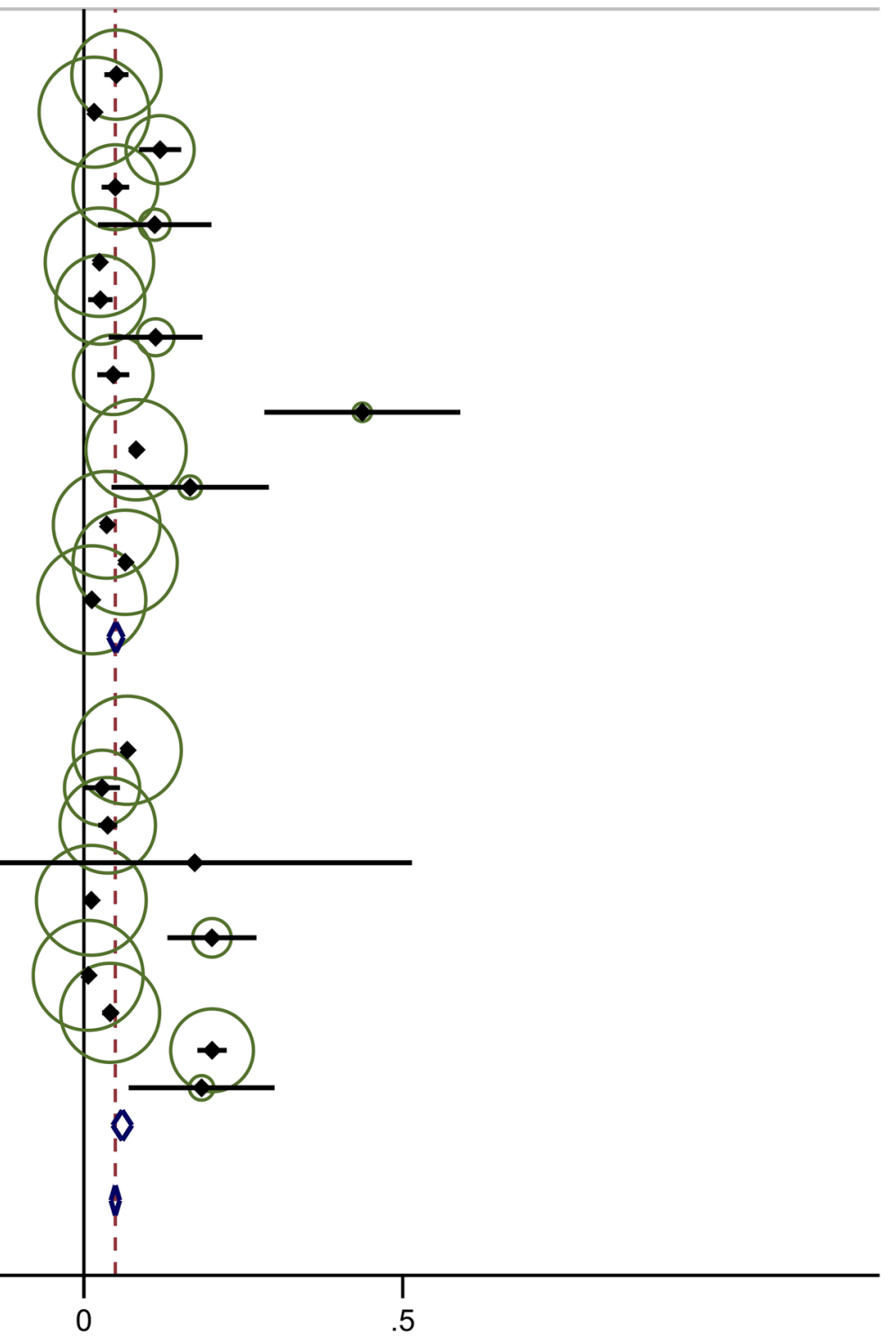

Fig. 3 a Background studies combined for SLNB and ALND. b BIS studies combined for SLNB and ALND. c Circumference studies with SLNB and ALND. Each study is represented by its estimated annualized incidence. The red dotted line is the overall pooled estimated annualized incidence. The light green circles represent the weight for each study to calculate the overall annualized incidence rate and are from the random-effects analysis. The diamond shapes are the variances for each cut point as well as the overall study variance 
ES $(95 \% \mathrm{Cl})$

$\%$ Weight

\section{GREATER THAN 50\%}

Laidley et al (2016) 51

Whitworth et al $(2018)^{64}$

Kaufman et al (2017) 8

Darragh et al (2018) 38

Subtotal

LESS THAN OR EQUAL 50\%

Erdogan lygun et al (2015) 40

Subtotal

Overall Annualized Incidence

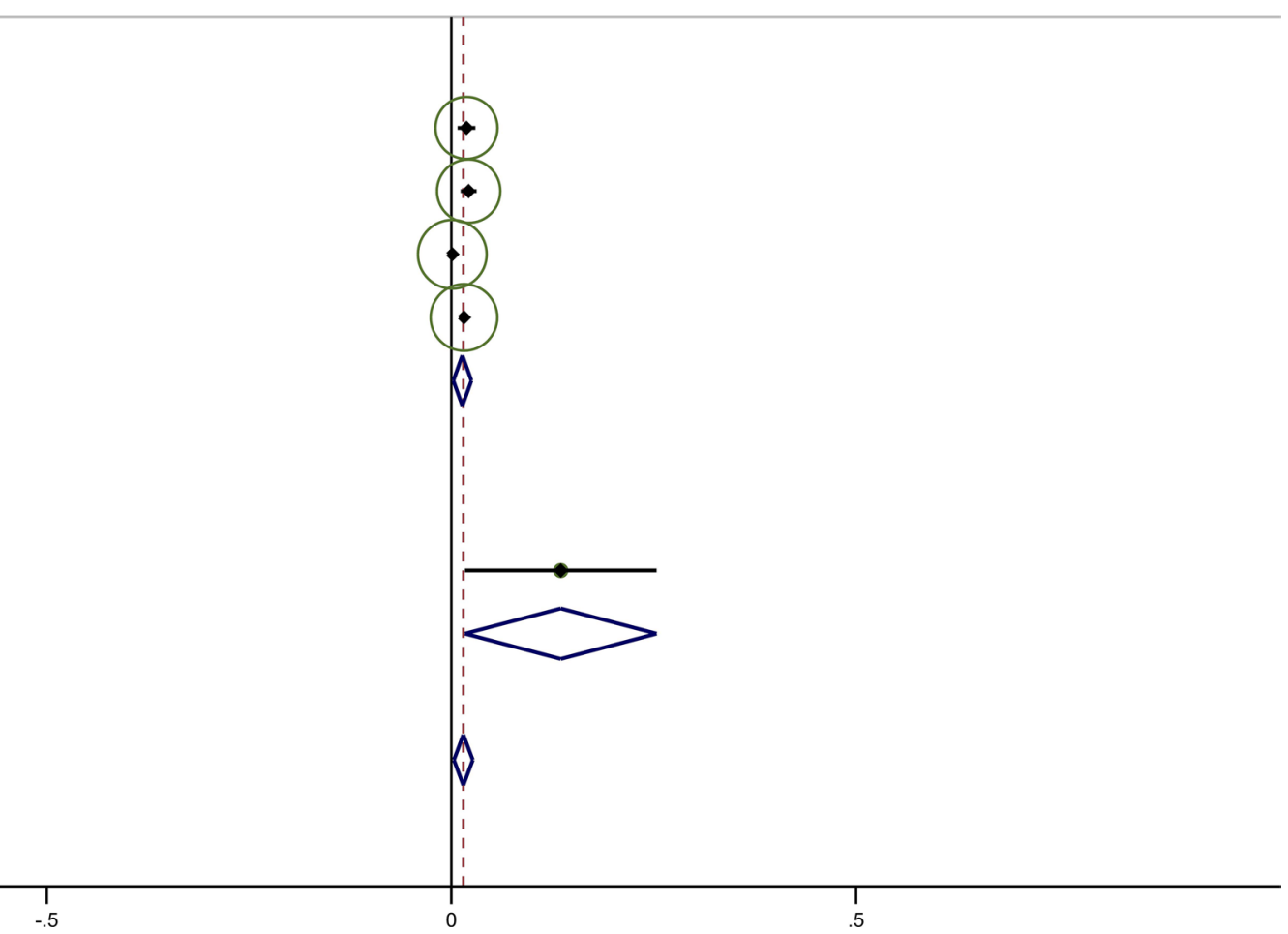

Fig. 3 (continued) 
Study ID

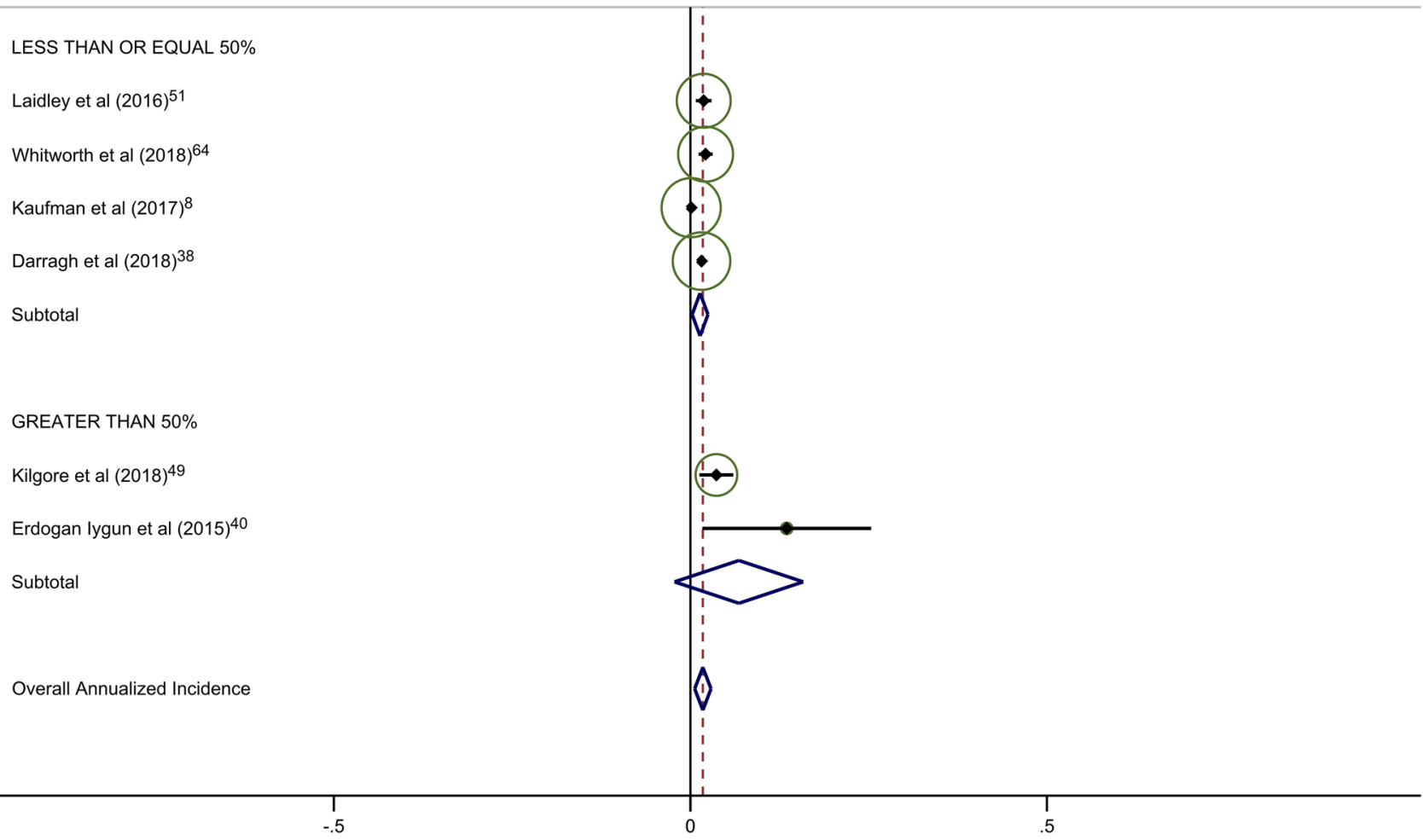

Fig. 3 (continued) 
Breast Cancer Research and Treatment (2021) 185:709-740

735

GREATER THAN 50\%

McLaughlin et al (2013) 53

Ballal et al $(2018)^{25}$

Wetzig et al (2017) 62

Ochalek et al $(2017)^{55}$

Blarney et al (2015) ${ }^{17}$

Lore et al (2019) 52

Subtotal

LESS THAN OR EQUAL 50\%

fArmer et al (2019) 16

fAy et al $(2014)^{23}$

Subtotal

Overall Annual Incidence

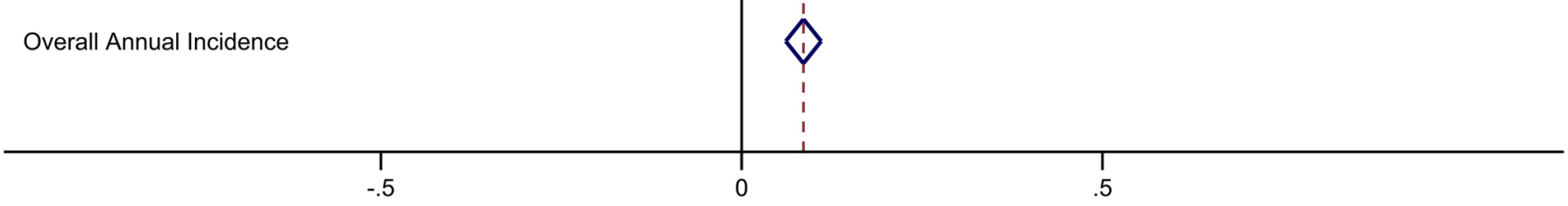

Fig. 3 (continued)

Springer 
Study ID

$\mathrm{ES}(95 \% \mathrm{Cl})$

$\%$ Weight

LESS THAN OR EQUAL 50\%

Fu et al (2014) 43

Coromilas et al (2016) 36

Black et al (2014) ${ }^{30}$

O'Toole et al (2013) ${ }^{56}$

Jammallo et al $(2014)^{47}$

Koehler et al (2018)50

Specht et al (2013)60

Gennaro et al $(2013)^{45}$

Bains et al (2014) $)^{24}$

Nguyen et al (2017) 54

Barrio et al (2015) $)^{26}$

Swaroop et al (2015)61

Berlit et al (2013) ${ }^{29}$

Basta et al (2017) ${ }^{27}$

Bulley et al (2014) $)^{33}$

Warren et al (2014) ${ }^{12}$

Jammallo et al (2013) ${ }^{47}$

Subtotal

GREATER THAN 50\%

Fu et al (2014) 44

Hopkins et al (2017)46

Ammitzboll et al (2017)21

Youssef et al (2016)65

Blaney et al (2015) ${ }^{17}$

Bloomquist et al (2014) ${ }^{31}$

Ammitzboll et al (2019)22

Cowher et al (2014) 37

Boccardo et al (2014) 32

Whelan et al (2015)63

Sagen et al (2014) $)^{57}$

Armer et al (2019) 16

Cariati et al (2015) $)^{34}$

De Groef et al (2017) 39

Feldman et al $(2015)^{41}$

Cintolesi et al (2016) 35

Subtotal

Overall Annualized Incidence

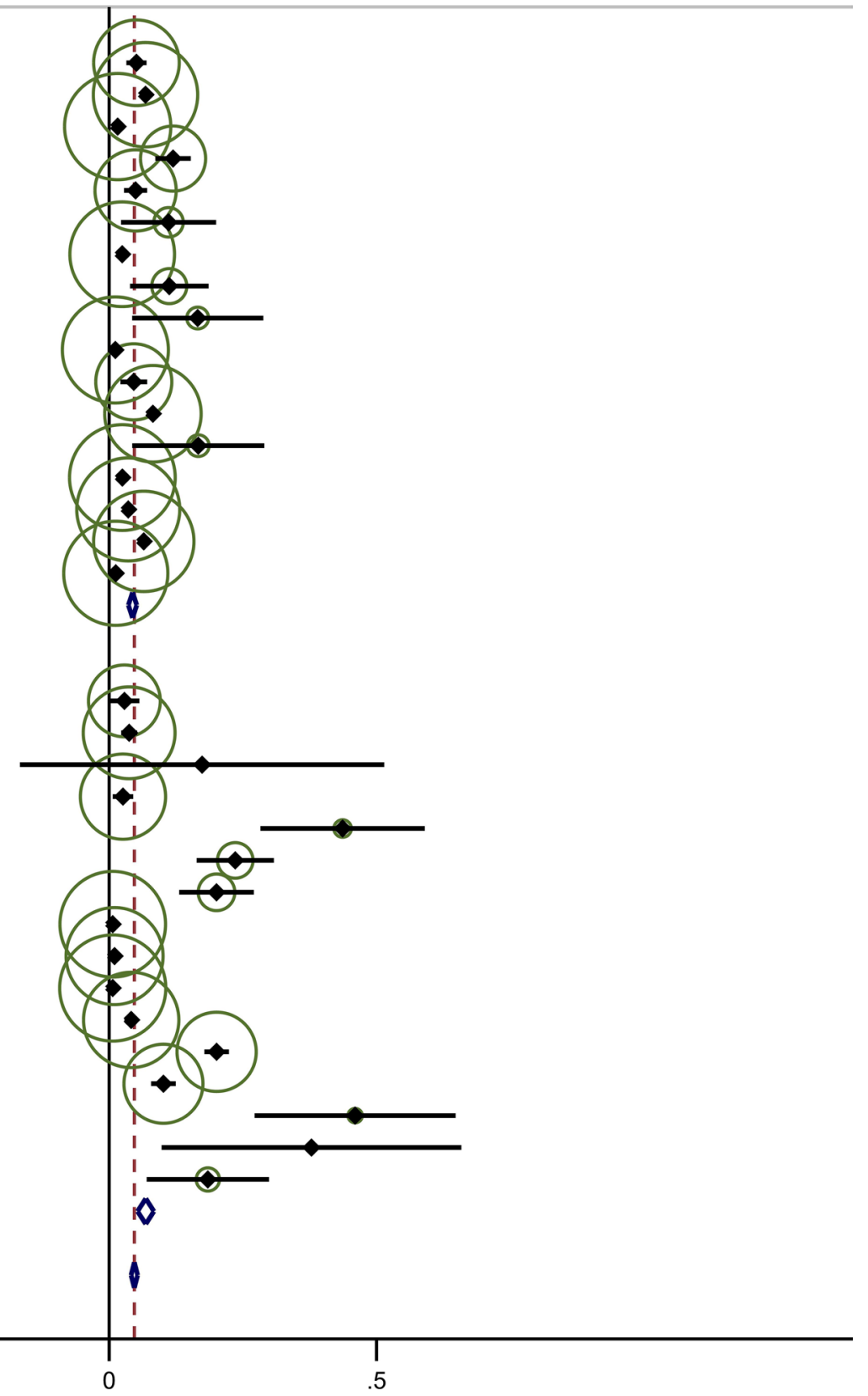

Fig. 3 (continued) 
Study ID

ES $(95 \% \mathrm{Cl})$

$\%$ Weight

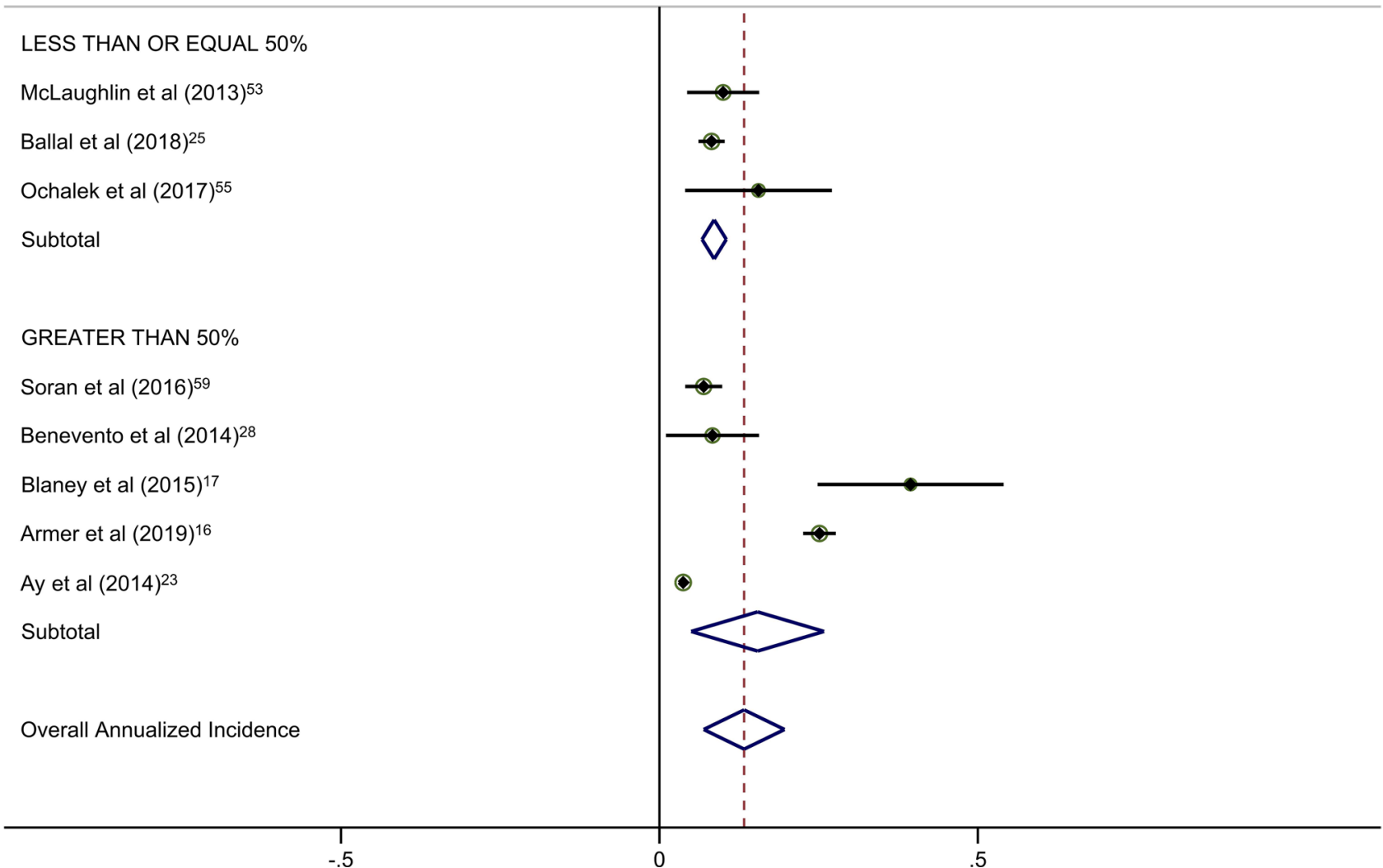

Fig. 3 (continued)

patients to develop BCRL and go undiagnosed, which can bias the results.

Acknowledgements We would like to thank Megan Burns, Carter Little, Ashley Pryor, and Case Zambelli for their assistance in project execution and reporting.

Funding This study was funded by ImpediMed, Inc.

\section{Compliance with ethical standards}

Conflict of interest Chirag Shah- Consultant ImpediMed and PreludeDX, Grant and Travel Expenses Varian Medical Systems, Grant- VisionRT, Grant- PreludeDx. April Zambelli-Weiner, Nicole Delgado, Ashley Sier, Robert Bauserman, Jerrod Nelms- Employed by TTi Health Research and Economics, who were provided funding for analysis

Ethics approval This article does not contain any studies with human participants performed by any of the authors.

Open Access This article is licensed under a Creative Commons Attribution 4.0 International License, which permits use, sharing, adaptation, distribution and reproduction in any medium or format, as long as you give appropriate credit to the original author(s) and the source, provide a link to the Creative Commons licence, and indicate if changes were made. The images or other third party material in this article are included in the article's Creative Commons licence, unless indicated otherwise in a credit line to the material. If material is not included in the article's Creative Commons licence and your intended use is not permitted by statutory regulation or exceeds the permitted use, you will need to obtain permission directly from the copyright holder. To view a copy of this licence, visit http://creativecommons.org/licenses/by/4.0/.

\section{References}

1. Shih Y-CT, Xu Y, Cormier JN et al (2009) Incidence, treatment costs, and complications of lymphedema after breast cancer among women of working age: a 2-year follow-up study. JCO 27(12):2007-2014. https://doi.org/10.1200/JCO.2008.18.3517

2. Dayes IS, Whelan TJ, Julian JA et al (2013) Randomized trial of decongestive lymphatic therapy for the treatment of lymphedema in women with breast cancer. JCO 31(30):37583763. https://doi.org/10.1200/JCO.2012.45.7192

3. Stout NL, Pfalzer LA, Springer B et al (2012) Breast cancerrelated lymphedema: comparing direct costs of a prospective surveillance model and a traditional model of care. Phys Ther 92(1):152-163. https://doi.org/10.2522/ptj.20100167

4. DiSipio T, Rye S, Newman B, Hayes S (2013) Incidence of unilateral arm lymphoedema after breast cancer: a systematic 
review and meta-analysis. Lancet Oncol 14(6):500-515. https ://doi.org/10.1016/S1470-2045(13)70076-7

5. Soran A, Ozmen T, McGuire KP et al (2014) The importance of detection of subclinical lymphedema for the prevention of breast cancer-related clinical lymphedema after axillary lymph node dissection; a prospective observational study. Lymphat Res Biol 12(4):289-294. https://doi.org/10.1089/lrb.2014.0035

6. Shaitelman SF, Cromwell KD, Rasmussen JC et al (2015) Recent progress in the treatment and prevention of cancerrelated lymphedema: Lymphedema Treatment and Prevention. CA Cancer J Clin. 65(1):55-81. https://doi.org/10.3322/ caac. 21253

7. Lawenda BD, Mondry TE, Johnstone PAS (2009) Lymphedema: a primer on the identification and management of a chronic condition in oncologic treatment. CA Cancer J Clin 59(1):8-24. https://doi.org/10.3322/caac.20001

8. Kaufman DI, Shah C, Vicini FA, Rizzi M (2017) Utilization of bioimpedance spectroscopy in the prevention of chronic breast cancer-related lymphedema. Breast Cancer Res Treat 166(3):809-815. https://doi.org/10.1007/s10549-017-4451-x

9. Warren AG, Brorson H, Borud LJ, Slavin SA (2007) Lymphedema: a comprehensive review. Ann Plast Surg 59(4):464-472. https:// doi.org/10.1097/01.sap.0000257149.42922.7e

10. Shah C, Arthur DW, Wazer D, Khan A, Ridner S, Vicini F (2016) The impact of early detection and intervention of breast cancer-related lymphedema: a systematic review. Cancer Med 5(6):1154-1162

11. Ward LC, Dylke E, Czerniec S, Isenring E, Kilbreath SL (2011) Reference ranges for assessment of unilateral lymphedema in legs by bioelectrical impedance spectroscopy. Lymphat Res Biol 9(1):43-46. https://doi.org/10.1089/lrb.2010.0024

12. Shah C (2019) Bioimpedance spectroscopy in the detection of breast cancer-related lymphedema: an ounce of prevention. Breast J 25(6):1323-1325. https://doi.org/10.1111/tbj.13618

13. PRISMA 2009 checklist. https://www.prisma-statement.org/.

14. Bown MJ, Sutton AJ (2010) Quality control in systematic reviews and meta-analyses. Eur J Vasc Endovasc Surg 40(5):669. https:// doi.org/10.1016/j.ejvs.2010.07.011

15. Armer JM, Ballman KV, McCall L et al (2019) Lymphedema symptoms and limb measurement changes in breast cancer survivors treated with neoadjuvant chemotherapy and axillary dissection: results of American College of Surgeons Oncology Group (ACOSOG) Z1071 (Alliance) substudy. Support Care Cancer 27(2):495-503. https://doi.org/10.1007/s00520-018-4334-7

16. Blaney JM, McCollum G, Lorimer J, Bradley J, Kennedy R, Rankin JP (2015) Prospective surveillance of breast cancer-related lymphoedema in the first-year post-surgery: feasibility and comparison of screening measures. Support Care Cancer. https://doi. org/10.1007/s00520-014-2504-9

17. Ridner SH, Dietrich MS, Cowher MS et al (2019) A randomized trial evaluating bioimpedance spectroscopy versus tape measurement for the prevention of lymphedema following treatment for breast cancer: interim analysis. Ann Surg Oncol. https://doi. org/10.1245/s10434-019-07344-5

18. Spittal MJ, Pirkis J, Gurrin LC (2015) Meta-analysis of incidence rate data in the presence of zero events. BMC Med Res Methodol. https://doi.org/10.1186/s12874-015-0031-0

19. Lane KN, Dolan LB, Worsley D, McKenzie DC (2007) Upper extremity lymphatic function at rest and during exercise in breast cancer survivors with and without lymphedema compared with healthy controls. J Appl Physiol (Bethesda, Md: 1985) 103(3):917-925. https://doi.org/10.1152/japplphysiol.00077.2007

20. Ammitzbøll G, Lanng C, Kroman N et al (2017) Progressive strength training to prevent LYmphoedema in the first year after breast Cancer-the LYCA feasibility study. Acta Oncol 56(2):360366. https://doi.org/10.1080/0284186X.2016.1268266
21. Ammitzbøll G, Johansen C, Lanng C et al (2019) Progressive resistance training to prevent arm lymphedema in the first year after breast cancer surgery: results of a randomized controlled trial. Cancer (0008543X) 125(10):1683-1692. https://doi. org/10.1002/cncr.31962

22. Ay AA, Kutun S, Cetin A (2014) Lymphoedema after mastectomy for breast cancer: importance of supportive care. S Afr J Surg 52(2):41-41. https://doi.org/10.7196/sajs.1908

23. Bains SK, Stanton AWB, Cintolesi V et al (2015) A constitutional predisposition to breast cancer-related lymphoedema and effect of axillary lymph node surgery on forearm muscle lymph flow. The Breast 24(1):68-74. https://doi.org/10.1016/j.breast.2014.11.010

24. Ballal H, Hunt C, Bharat C, Murray K, Kamyab R, Saunders C (2018) Arm morbidity of axillary dissection with sentinel node biopsy versus delayed axillary dissection. ANZ J Surg 88(9):917921. https://doi.org/10.1111/ans.14382

25. Barrio AV, Eaton A, Frazier TG (2015) A prospective validation study of bioimpedance with volume displacement in early-stage breast cancer patients at risk for lymphedema. Ann Surg Oncol. https://doi.org/10.1245/s10434-015-4683-0

26. Basta MN, Wu LC, Kanchwala SK et al (2017) Reliable prediction of postmastectomy lymphedema: the risk assessment tool evaluating lymphedema. Am J Surg 213(6):1125-1133.e1. https ://doi.org/10.1016/j.amjsurg.2016.08.016

27. Benevento R, Santoriello A, Pellino G et al (2014) The effects of low-thrombin fibrin sealant on wound serous drainage, seroma formation and length of postoperative stay in patients undergoing axillary node dissection for breast cancer. A randomized controlled trial. Int J Surg (London, England). 12(11):1210-1215. https://doi.org/10.1016/j.ijsu.2014.10.005

28. Berlit S, Brade J, Tuschy B et al (2013) Whole-body bioelectrical impedance analysis in assessing upper-limb lymphedema after breast cancer therapy. Anticancer Res 33(10):4553-4556

29. Black DM, Jiang J, Kuerer HM, Buchholz TA, Smith BD (2014) Racial disparities in adoption of axillary sentinel lymph node biopsy and lymphedema risk in women with breast cancer. JAMA surgery 149(8):788-796. https://doi.org/10.1001/jamas urg.2014.23

30. Bloomquist K, Karlsmark T, Christensen KB, Adamsen L (2014) Heavy resistance training and lymphedema: prevalence of breast cancer-related lymphedema in participants of an exercise intervention utilizing heavy load resistance training. Acta Oncol 53(2):216-225. https://doi.org/10.3109/0284186X.2013.844356

31. Boccardo F, Casabona F, Decian F et al (2014) Lymphatic microsurgical preventing healing approach (LYMPHA) for primary surgical prevention of breast cancer-related lymphedema: over 4 years follow-up. Microsurgery 34(6):421-424. https://doi. org/10.1002/micr.22254

32. Bulley C, Coutts F, Blyth C et al (2014) A morbidity screening tool for identifying fatigue, pain, upper limb dysfunction and lymphedema after breast cancer treatment: a validity study. Eur J Oncol Nurs 18(2):218-227. https://doi.org/10.1016/j. ejon.2013.10.006

33. Cariati M, Bains SK, Grootendorst MR et al (2015) Adjuvant taxanes and the development of breast cancer-related arm lymphoedema. Br J Surg. https://doi.org/10.1002/bjs.9846

34. Cintolesi V, Stanton AWB, Bains SK et al (2016) Constitutively enhanced lymphatic pumping in the upper limbs of women who later develop breast cancer-related lymphedema. Lymphat Res Biol 14(2):50-61. https://doi.org/10.1089//rb.2016.0005

35. Coromilas EJ, Wright JD, Huang Y et al (2016) Axillary evaluation and lymphedema in women with ductal carcinoma in situ. Breast Cancer Res Treat 158(2):373-384. https://doi.org/10.1007/ s10549-016-3890-0

36. Cowher MS, Grobmyer SR, Lyons J, O'Rourke C, Baynes D, Crowe JP (2014) Conservative axillary surgery in breast cancer 
patients undergoing mastectomy: long-term results. J Am Coll Surg 218(4):819-824. https://doi.org/10.1016/j.jamcollsur g.2013.12.041

37. Darragh L, McGuinness E, Kirk SJ (2018) Prospective surveillance with bioelectrical impedance to guide early treatment of breast cancer-related lymphoedema. Int Wound J 9(4):39-43

38. De Groef A, Van Kampen M, Verlvoesem N et al (2017) Effect of myofascial techniques for treatment of upper limb dysfunctions in breast cancer survivors: randomized controlled trial. Support Care Cancer 25(7):2119-2127. https://doi.org/10.1007/s0052 0-017-3616-9

39. Erdogan Iyigun Z, Selamoglu D, Alco G et al (2015) Bioelectrical impedance for detecting and monitoring lymphedema in patients with breast cancer. Preliminary results of the florence nightingale breast study group. Lymphat Res Biol 13(1):40-45. https://doi. org/10.1089/lrb.2014.0014

40. Feldman S, Bansil H, Ascherman J et al (2015) Single institution experience with lymphatic microsurgical preventive healing approach (LYMPHA) for the primary prevention of lymphedema. Ann Surg Oncol 22(10):3296-3301. https://doi.org/10.1245/s1043 4-015-4721-y

41. Fu MR, Axelrod D, Guth AA et al (2015) Patterns of obesity and lymph fluid level during the first year of breast cancer treatment: a prospective study. J Pers Med 5(3):326-340. https://doi. org/10.3390/jpm5030326

42. Fu MR, Axelrod D, Guth AA et al (2014) Proactive approach to lymphedema risk reduction: a prospective study. Ann Surg Oncol 21(11):3481-3489. https://doi.org/10.1245/s10434-014-3761-z

43. Fu Y, Chung D, Cao M-A, Apple S, Chang H (2014) Is axillary lymph node dissection necessary after sentinel lymph node biopsy in patients with mastectomy and pathological N1 breast cancer? Ann Surg Oncol 21(13):4109-4123. https://doi.org/10.1245/s1043 4-014-3814-3

44. Gennaro M, MacCauro M, Sigari C et al (2013) Selective axillary dissection after axillary reverse mapping to prevent breast-cancerrelated lymphoedema. Eur J Surg Oncol 39(12):1341-1345. https ://doi.org/10.1016/j.ejso.2013.09.022

45. Hopkins JO, Allred J, Hurria A et al (2017) Lymphedema, musculoskeletal events and arm function in older patients receiving adjuvant chemotherapy for breast cancer (Alliance A171302). Breast Cancer Res Treat 166(3):793-808. https://doi.org/10.1007/s1054 9-017-4454-7

46. Jammallo LS, Miller CL, Horick NK et al (2014) Factors associated with fear of lymphedema after treatment for breast cancer. Oncol Nurs Forum 41(5):473-483. https://doi.org/10.1188/14. ONF.473-483

47. Jammallo LS, Miller CL, Singer M et al (2013) Impact of body mass index and weight fluctuation on lymphedema risk in patients treated for breast cancer. Breast Cancer Res Treat 142(1):59-67. https://doi.org/10.1007/s10549-013-2715-7

48. Kilgore LJ, Korentager SS, Hangge AN et al (2018) Reducing breast cancer-related lymphedema (BCRL) through prospective surveillance monitoring using bioimpedance spectroscopy (BIS) and patient directed self-interventions. Ann Surg Oncol 25(10):2948-2952. https://doi.org/10.1245/s10434-018-6601-8

49. Koehler LA, Hunter DW, Blaes AH, Haddad TC (2018) Function, shoulder motion, pain, and lymphedema in breast cancer with and without axillary web syndrome: an 18-month follow-up. Phys Ther 98(6):518-527. https://doi.org/10.1093/ptj/pzy010

50. Laidley A, Anglin B (2016) The impact of L-Dex(®) measurements in assessing breast cancer-related lymphedema as part of routine clinical practice. Front Oncol 6:192-192. https://doi. org/10.3389/fonc.2016.00192

51. Lorek A, Stojčev Z, Zarębski W, Kowalczyk M, Szyluk K (2019) Analysis of postoperative complications after 303 sentinel lymph node identification procedures using the SentiMag® method in breast cancer patients. Med Sci Mon Int Med J Exp Clin 25:31543160. https://doi.org/10.12659/MSM.912758

52. McLaughlin SA, Bagaria S, Gibson T et al (2013) Trends in risk reduction practices for the prevention of lymphedema in the first 12 months after breast cancer surgery. J Am Coll Surg 216(3):380 389. https://doi.org/10.1016/j.jamcollsurg.2012.11.004

53. Nguyen TT, Hoskin TL, Habermann EB, Cheville AL, Boughey JC (2017) Breast cancer-related lymphedema risk is related to multidisciplinary treatment and not surgery alone: results from a large cohort study. Breast Oncol 24(10):2972-2980. https://doi. org/10.1245/s10434-017-5960-x

54. Ochalek K, Gradalski T, Partsch H (2017) Preventing early postoperative arm swelling and lymphedema manifestation by compression sleeves after axillary lymph node interventions in breast cancer patients: a randomized controlled trial. J Pain Symptom Manage 54(3):346-354. https://doi.org/10.1016/j.jpainsymma n.2017.04.014

55. O'Toole J, Miller CL, Specht MC et al (2013) Cording following treatment for breast cancer. Breast Cancer Res Treat 140(1):105111. https://doi.org/10.1007/s10549-013-2616-9

56. Sagen A, Kaaresen R, Sandvik L, Thune I, Risberg MA (2014) Upper limb physical function and adverse effects after breast cancer surgery: a prospective 2.5-year follow-up study and preoperative measures. Arch Phys M 95(5):875-881. https://doi. org/10.1016/j.apmr.2013.12.015

57. Skuli SJ, Sheng JY, Bantug ET et al (2019) Survivorship care visits in a high-risk population of breast cancer survivors. Breast Cancer Res Treat 173(3):701-708. https://doi.org/10.1007/s1054 9-018-5028-Z

58. Soran A, Menekse E, Girgis M, DeGore L, Johnson R (2016) Breast cancer-related lymphedema after axillary lymph node dissection: does early postoperative prediction model work? Support Care Cancer 24(3):1413-1419. https://doi.org/10.1007/s0052 0-015-2933-0

59. Specht MC, Miller CL, Russell TA et al (2013) Defining a threshold for intervention in breast cancer-related lymphedema: what level of arm volume increase predicts progression? Breast Cancer Res Treat. https://doi.org/10.1007/s10549-013-2655-2

60. Swaroop MN, Ferguson CM, Horick NK et al (2015) Impact of adjuvant taxane-based chemotherapy on development of breast cancer-related lymphedema: results from a large prospective cohort. Breast Cancer Res Treat 151(2):393-403. https://doi. org/10.1007/s10549-015-3408-1

61. Wetzig N, Gill PG, Espinoza D et al (2017) Sentinel-lymph-nodebased management or routine axillary clearance? five-year outcomes of the RACS sentinel node biopsy versus axillary clearance (SNAC) 1 trial: assessment and incidence of true lymphedema. Ann Surg Oncol 24(4):1064-1070. https://doi.org/10.1245/s1043 4-016-5669-2

62. Whelan TJ, Olivotto IA, Parulekar WR et al (2015) Regional nodal irradiation in early-stage breast cancer. N Engl J Med 373(4):307-316. https://doi.org/10.1056/NEJMoa1415340

63. Whitworth PW, Cooper A (2018) Reducing chronic breast cancerrelated lymphedema utilizing a program of prospective surveillance with bioimpedance spectroscopy. Breast J 24(1):62-65. https://doi.org/10.1111/tbj.12939

64. Youssef MMG, Cameron D, Pucher PH, Olsen S, Ferguson D (2016) The significance of sentinel lymph node micrometastasis in breast cancer: comparing outcomes with and without axillary clearance. Breast (Edinburgh, Scotland) 30:101-104. https://doi. org/10.1016/j.breast.2016.09.00

65. Warren LEG, Miller CL, Horick N et al (2014) The impact of radiation therapy on the risk of lymphedema after treatment for breast cancer: a prospective cohort study. Int J Radiat Oncol Biol Phys 88(3):565-571. https://doi.org/10.1016/j.ijrobp.2013.11.232 
66. Vicini F, Shah C, Lyden M et al (2012) Bioelectrical impedance for detecting and monitoring patients for the development of upper limb lymphedema in the clinic. Clin Breast Cancer 12:133-137

67. Shah C, Vicini F, Arthur D (2016) Bioimpedance spectroscopy for breast cancer related lymphedema assessment: clinical practice guidelines. Breast J 22:645-650
68. Ridner SH, Dietrich MS, Spotanski K et al (2018) A prospective study of L-Dex values in breast cancer patients pretreatment and through 12 months postoperatively. Lymphat Res Biol 16:435-441

Publisher's Note Springer Nature remains neutral with regard to jurisdictional claims in published maps and institutional affiliations. 